\title{
Flexible and High-Performance Electrochromic Devices Enabled by Self-Assembled 2D TiO2/MXene Heterostructures
}

\section{Ran Li}

Donghua University, Boston University

\section{Xiaoyuan Ma}

Boston University

Jianmin Li

Donghua University

Jun Cao

Boston University

Hongze Gao

Boston University

\section{Tianshu Li}

Boston University

\section{Xiaoyu Zhang}

Donghua University

\section{Lichao Wang}

Donghua University

\section{Qinghong Zhang}

Donghua University https://orcid.org/0000-0002-4373-7665

\section{Gang Wang}

Donghua University

\section{Chengyi Hou}

Donghua University

\section{Yaogang Li}

Donghua University

\section{Tomas Palacios}

Massachusetts Institute of Technology

Yuxuan Lin

UC Berkeley https://orcid.org/0000-0003-0638-2620

\section{Hongzhi Wang}

State Key Laboratory for Modification of Chemical Fibers and Polymer Materials, College of Materials 


\section{Xi Ling ( $\boldsymbol{D}$ xiling@bu.edu )}

Boston University

\section{Article}

Keywords: Transition metal oxides, TMO, MXenes, EC devices, large-area flexible devices

Posted Date: July 28th, 2020

DOI: https://doi.org/10.21203/rs.3.rs-45725/v1

License: (c) (1) This work is licensed under a Creative Commons Attribution 4.0 International License. Read Full License

Version of Record: A version of this preprint was published at Nature Communications on March 11th, 2021. See the published version at https://doi.org/10.1038/s41467-021-21852-7. 
Flexible and High-Performance Electrochromic Devices Enabled by Self-Assembled 2D $\mathrm{TiO}_{2} / \mathrm{MXene}$ Heterostructures

Ran $\mathrm{Li}^{1,2} \uparrow$, Xiaoyuan $\mathrm{Ma}^{2} \uparrow$, Jianmin $\mathrm{Li}^{1}$, Jun $\mathrm{Cao}^{2}$, Hongze Gao ${ }^{4}$, Tianshu $\mathrm{Li}^{4}$, Xiaoyu Zhang ${ }^{1}$, Lichao Wang ${ }^{1}$, Qinghong Zhang ${ }^{1}$, Gang Wang ${ }^{1}$, Chengyi Hou ${ }^{1}$, Yaogang Li ${ }^{1}$, Tomás Palacios ${ }^{3}$, Yuxuan Lin ${ }^{3 * \#}$, Hongzhi Wang ${ }^{1 *}$, and Xi Ling ${ }^{2,4,5^{*}}$

${ }^{1}$ State Key Laboratory for Modification of Chemical Fibers and Polymer Materials, College of Materials Science and Engineering, Donghua University, Shanghai 201620, China.

${ }^{2}$ Department of Chemistry, Boston University, 590 Commonwealth Avenue, Boston, MA 02215, USA.

${ }^{3}$ Department of Electrical Engineering and Computer Science, Massachusetts Institute of Technology, Cambridge, MA 02139, USA.

${ }^{4}$ Division of Materials Science and Engineering, Boston University, 15 St. Mary's street, Boston, MA 02215, USA.

${ }^{5}$ The Photonics Center, Boston University, 8 St. Mary’s street, Boston, MA 02215, USA.

$\dagger$ These authors contributed equally to this work.

*Correspondence to: (X.L.) $\quad \underline{\text { xiling@bu.edu; }} \quad$ (H.W.) wanghz@dhu.edu.cn; $\quad$ (Y.L.) yxlin@,berkeley.edu

${ }^{\#}$ Current address: Department of Electrical Engineering and Computer Sciences, University of California, Berkeley, CA 94720, USA. 


\begin{abstract}
Transition metal oxides (TMO) are promising electrochromic (EC) materials for applications such as smart windows and displays, yet challenge still exists to achieve good flexibility, high coloration efficiency and fast response simultaneously. MXenes (e.g. Ti3 $\mathrm{C}_{2} \mathrm{~T}_{\mathrm{x}}$ ) and their derived TMOs (e.g. 2D $\mathrm{TiO}_{2}$ ) are good candidates for high-performance and flexible EC devices because of their 2D nature and the possibility of assembling them into loosely networked structures. Here we demonstrate flexible, fast, and high-coloration-efficiency EC devices based on self-assembled $2 \mathrm{D} \mathrm{TiO}_{2} / \mathrm{Ti}_{3} \mathrm{C}_{2} \mathrm{~T}_{\mathrm{x}}$ heterostructures, with the $\mathrm{Ti}_{3} \mathrm{C}_{2} \mathrm{~T}_{x}$ layer as the transparent electrode, and the $2 \mathrm{D} \mathrm{TiO}_{2}$ layer as the $\mathrm{EC}$ layer. Benefiting from the well-balanced porosity and connectivity of these assembled nanometer-thick heterostructures, they present fast and efficient ion and electron transport, as well as superior mechanical and electrochemical stability. We further demonstrate large-area flexible devices which could potentially be integrated onto curved and flexible surfaces for future ubiquitous electronics.
\end{abstract}




\section{Introduction}

Electrochromic (EC) materials, which can change their optical absorption reversibly due to the electrochemical redoxation with inserted ions under an applied potential (1-3), have shown great promise in applications such as displays, smart windows and optical camouflage (3-5). With the growing interest in bringing electrochromism to the field of flexible and wearable electronics in recent years, incorporating the functionality of flexibility to EC devices while maintaining high energy efficiency, fast switching speed and long durability has become increasingly critical $(6,7)$. However, this is an extremely challenging task because: (a) both the EC performance and the mechanical properties are non-trivially correlated with the materials of choice, their nanoscale formations, and the assembly approach; and (b) the co-optimization of the transparent conductive electrode and the EC material, as well as the way to integrate them is needed.

Recently, two-dimensional (2D) transition metal carbides, nitrides, and carbonitrides (referred to as MXenes) have emerged $(8,9)$ as promising nanoscale electronic materials with good electrochemical stability. They have also been reported as promising templates for the synthesis of functional micro/nano-structured materials such as transition metal oxides (TMOs), alkali-metal titanates, and their hybrids $(10,11)$. Owing to their unique optical and electrical properties, MXenes and their derivatives have demonstrated their potential in the application of energy storage, catalysis and electronics (12-14). More importantly, 2D nanosheets of both MXenes and their derivatives can be produced in liquid phase scalably, which makes it easy for constructing self-assembled films and hybrid structures, suitable for device applications in large scale.

We propose that self-assembled MXene/TMO heterostructures, with the MXenes as the flexible transparent electrode, and the TMOs (derived from the MXenes) as the flexible EC layer, are ideal for high-performance and flexible EC devices, yet it has never been explored previously. In addition to the advantage of the easiness of fabrication and integration with different functional 
components from MXene derivatives as mentioned above, an even more important reason is that the nanosheets network of TMOs, such as tungsten oxide ( $\left.\mathrm{WO}_{3}\right)$ and titanium oxide $\left(\mathrm{TiO}_{2}\right)$, can potentially realize not only superior EC properties, but also reliable mechanical and chemical stability among various candidates of EC materials. First, these inorganic materials are long-lasting and robust against environmental factors such as high temperature, ultraviolet radiation, and mechanical wear (15-17), as compared to their organic counterparts (18). Second, the nanostructured TMO network, especially in the form of 2D nanosheets, improves electrical and ionic transport significantly, because: (a) the increased surface-to-volume ratio of nanosheets as compared to the bulk forms leads to larger interface areas with the electrolyte and the shorter ion diffusivity pathways within the nanostructured channels $(3,19)$; and (b) the 2D formation of the nanostructures makes the contact area between adjacent nanosheets much bigger than that between 1D or 0D structures (nanowires or quantum dots) (20), which promotes the inter-nanosheets electron transfer (21). Finally, networks of 2D nanostructures also helps to redistribute the induced strain more evenly, thus improving both the mechanical strength and the flexibility of the film, which is fundamentally more advantageous than 1D or 0D nanostructures (22).

As a proof-of-concept demonstration, we sucessfully assemble $\mathrm{Ti}_{3} \mathrm{C}_{2} \mathrm{~T}_{\mathrm{x}}(\mathrm{T}=\mathrm{O}, \mathrm{OH}$ or $\mathrm{F})$ and the derived $\mathrm{TiO}_{2}$ nanosheets into uniform nanometer-thick films at a liquid-liquid interface, and fabricate EC devices based on the $\mathrm{TiO}_{2} / \mathrm{Ti}_{3} \mathrm{C}_{2} \mathrm{~T}_{x}$ heterostructures on a flexible substrate. Due to the excellent ion and electron conductivity of assembled single-flake-layer $\mathrm{TiO}_{2}$ film and the 2D nature of both the MXene electrodes and the $\mathrm{TiO}_{2} \mathrm{EC}$ layer, our devices are among the best flexible EC devices with the fastest coloration speed, the highest coloration efficiency and superior electrochemical stability. We further demonstrate a large-area flexible device which could potentially be integrated with arbitrary curved and flexible surfaces for future ubiquitous electronics. 


\section{Results}

\section{Fabrication of $\mathrm{TiO}_{2} / \mathrm{Ti}_{3} \mathrm{C}_{2} \mathrm{~T}_{x}$ heterostructures}

Fig. 1 illustrates the fabrication process of the self-assembled $\mathrm{TiO}_{2} / \mathrm{Ti}_{3} \mathrm{C}_{2} \mathrm{~T}_{\mathrm{x}}$ heterostructure on a flexible structure as the core functional component of EC devices. The fabrication process consists of three steps: First, the $\mathrm{Ti}_{3} \mathrm{C}_{2} \mathrm{~T}_{\mathrm{x}}$ nanosheet dispersion in deionized (DI) water is obtained from selective etching of $\mathrm{Ti}_{3} \mathrm{AlC}_{2}$ powder (MAX phase) (23), and diluted to $0.2 \mathrm{mg} / \mathrm{L}$, followed by the formation of the $\mathrm{Ti}_{3} \mathrm{C}_{2} \mathrm{~T}_{\mathrm{x}}$ aerogel through freeze-drying. The $\mathrm{Ti}_{3} \mathrm{C}_{2} \mathrm{~T}_{\mathrm{x}}$ aerogel is then annealed in air at $400^{\circ} \mathrm{C}$ to fully convert the $\mathrm{Ti}_{3} \mathrm{C}_{2} \mathrm{~T}_{\mathrm{x}}$ aerogel to the $\mathrm{TiO}_{2}$ aerogel. Second, the $\mathrm{Ti}_{3} \mathrm{C}_{2} \mathrm{~T}_{\mathrm{x}}\left(\mathrm{TiO}_{2}\right)$ aerogels are dispersed into isopropyl alcohol (IPA) to form the $\mathrm{Ti}_{3} \mathrm{C}_{2} \mathrm{~T}_{\mathrm{x}}\left(\mathrm{TiO}_{2}\right)$ solutions, which are then injected into the interface between hexane and water, where the nanosheets self-assemble into uniform nanometer-thick films; Last, the self-assembled $\mathrm{Ti}_{3} \mathrm{C}_{2} \mathrm{~T}_{\mathrm{x}}$ film and $\mathrm{TiO}_{2}$ film are transferred sequentially onto a flexible polyethylene terephthalate (PET) substrate to form $\mathrm{TiO}_{2} / \mathrm{Ti}_{3} \mathrm{C}_{2} \mathrm{~T}_{\mathrm{x}}$ heterostructures, in which the $\mathrm{Ti}_{3} \mathrm{C}_{2} \mathrm{~T}_{\mathrm{x}}$ film serves as the transparent conductive electrode, and the $\mathrm{TiO}_{2}$ film serves as the EC layer in EC devices.

To obtained anatase phase of $\mathrm{TiO}_{2}$, which has been demonstrated a good EC materials (24), we anneal the $\mathrm{Ti}_{3} \mathrm{C}_{2} \mathrm{~T}_{\mathrm{x}}$ aerogel in air at $400^{\circ} \mathrm{C}$ for $50 \mathrm{~h}$. X-ray diffraction (XRD) and Raman spectroscopy of the flakes are measured before and after the thermal annealing process to investigate the compositional and the structural changes. As shown in Fig. 2A, after annealing in air at $400^{\circ} \mathrm{C}$, new peaks at $26^{\circ}, 38^{\circ}, 48^{\circ}, 54^{\circ}$ and $63^{\circ}$ appear in the XRD spectra, corresponding to the (101), (112), (200), (105) and (204) planes of anatase phase of $\mathrm{TiO}_{2}(25)$. Raman spectra of $\mathrm{Ti}_{3} \mathrm{C}_{2} \mathrm{~T}_{\mathrm{x}}$ flakes after annealing confirms the conversion from $\mathrm{Ti}_{3} \mathrm{C}_{2} \mathrm{~T}_{\mathrm{x}}$ to $\mathrm{TiO}_{2}$ (Fig. 2B), where peaks at $145 \mathrm{~cm}^{-1}\left(\mathrm{E}_{\mathrm{g}}\right), 398 \mathrm{~cm}^{-1}\left(\mathrm{~B}_{1 \mathrm{~g}}\right), 518 \mathrm{~cm}^{-1}\left(\mathrm{~B}_{1 \mathrm{~g}}\right)$, and $639 \mathrm{~cm}^{-1}\left(\mathrm{E}_{\mathrm{g}}\right)$ match well with the Raman features of anatase phase of $\mathrm{TiO}_{2}$ (26). X-ray photoelectron spectroscopy (XPS) 
characterization further suggests the transformation from $\mathrm{Ti}_{3} \mathrm{C}_{2} \mathrm{~T}_{\mathrm{x}}$ to $\mathrm{TiO}_{2}$. It's clearly seen that the peaks for the Ti element in $\mathrm{Ti}_{3} \mathrm{C}_{2} \mathrm{~T}_{x}$ (i.e. Ti-C $2 \mathrm{p}_{3 / 2}(455.3 \mathrm{eV})$, Ti(II) $2 \mathrm{p}_{3 / 2}(456.1 \mathrm{eV})$, Ti(III) $2 \mathrm{p}_{3 / 2}$ (457.2)) disappear after the annealing (Fig. 2C top and Fig. S1), while peaks at $458.8 \mathrm{eV}$ and $464.8 \mathrm{eV}$, corresponding to $\mathrm{Ti}(\mathrm{IV}) 2 \mathrm{p}_{3 / 2}$ and $\mathrm{Ti}(\mathrm{IV}) 2 \mathrm{p}_{1 / 2}$ in $\mathrm{TiO}_{2}$, become dominant (Fig. $2 \mathrm{C}$ bottom) (27).

To evaluate the morphology and crystallinity of the obtained $\mathrm{TiO}_{2}$ nanosheets, optical microscopy (OM), transmission electron microscopy (TEM) and atomic force microscopy (AFM) are used to characterize individual flakes of the $\mathrm{Ti}_{3} \mathrm{C}_{2} \mathrm{~T}_{\mathrm{x}}$ and the converted $\mathrm{TiO}_{2}$. Fig. S2 shows the $\mathrm{OM}$ images of a typical flake undergoing the annealing treatment at $400^{\circ} \mathrm{C}$ for $50 \mathrm{~h}$, where the morphology of the flake maintains in the process, the typical flake sizes are around $7 \mu \mathrm{m}$. The typical TEM images (Fig. 2D and 2E) and the selective area electron diffraction (SAED) patterns (insets of Fig. 2D and 2E) indicate that both $\mathrm{Ti}_{3} \mathrm{C}_{2} \mathrm{~T}_{\mathrm{x}}$ and $\mathrm{TiO}_{2}$ are in good crystallinity. The AFM images as shown in Fig. $\mathbf{S 3}$ and Fig. 2F suggest that the transformation from $\mathrm{Ti}_{3} \mathrm{C}_{2} \mathrm{~T}_{\mathbf{x}}$ to $\mathrm{TiO}_{2}$ maintains its $2 \mathrm{D}$ nature with smooth surface. The typical thickness of the anatase $\mathrm{TiO}_{2}$ flakes is about $2 \mathrm{~nm}$ (Fig. 2F), which is similar to that of $\mathrm{Ti}_{3} \mathrm{C}_{2} \mathrm{~T}_{\mathrm{x}}$ flakes (Fig. S3). Although the crystal lattice is transformed drastically from hexagonal $\left(\mathrm{Ti}_{3} \mathrm{C}_{2} \mathrm{~T}_{\mathrm{x}}\right)$ to tetragonal (anatase $\mathrm{TiO}_{2}$ ), our results clearly demonstrate the successful production of $\mathrm{Ti}_{3} \mathrm{C}_{2} \mathrm{~T}_{\mathrm{x}}$ flakes and their derived $\mathrm{TiO}_{2}$ flakes, both of which are high quality crystals with nanometer-scale thicknesses and micrometer-scale sizes. In contrast, the crystal structures collapse and re-organize into amorphous or nanoparticles of $\mathrm{TiO}_{2}$ during the oxidation treatment in previous reports (10). We believe that our result is due to the confined reaction on the initial $2 \mathrm{D} \mathrm{Ti}_{3} \mathrm{C}_{2} \mathrm{~T}_{\mathrm{x}}$ flakes, and their good separation from each other in the skeleton of aerogels during the conversion process helps remain the reaction on each $2 \mathrm{D}$ 
$\mathrm{Ti}_{3} \mathrm{C}_{2} \mathrm{~T}_{\mathrm{x}}$ flake, which is consistent with our previous results about the conversion from $\mathrm{MoS}_{2}$ flakes to ultrathin $\mathrm{Mo}_{5} \mathrm{~N}_{6}$ flakes on $\mathrm{SiO}_{2} / \mathrm{Si}$ substrates with maintained crystallinity (28).

\section{Self-assembled ultrathin MXene films as high-performance transparent electrodes}

To obtain large-area homogeneous thin films of the $\mathrm{TiO}_{2}$ or $\mathrm{Ti}_{3} \mathrm{C}_{2} \mathrm{~T}_{\mathrm{x}}$ network, a liquid/liquid interfacial self-assembly (LLIA) technique is used (29). Specifically, the 2D flakes/IPA dispersion is injected to the interface between hexane and water. Because of the fast dissolution of IPA into the hexane layer, a surface tension gradient is established along the interface (Marangoni force) (30). Driving by this Marangoni force, the 2D flakes spreads out quickly and settles at the edge of the liquid interface, that is, either the sidewall of the container or the edge of an already assembled film. By optimizing the amount of the injected 2D flakes/IPA solution, a full coverage is achieved and a continuous 2D thin film is obtained. As shown in the OM image of Fig. 3A, the LLIA $\mathrm{Ti}_{3} \mathrm{C}_{2} \mathrm{~T}_{\mathrm{x}}$ film is homogeneous over a large area. According to the AFM image (Fig. 3B and Fig. S4) taken at the selected area in Fig. 3A, the $\mathrm{Ti}_{3} \mathrm{C}_{2} \mathrm{~T}_{\mathrm{x}}$ flakes are all horizontally oriented, and placed next to each other with very small overlaps. This is very different from the films produced by the spray coating or spin coating methods where the orientations of the flakes are randomly distributed, and they are mostly overlapped and bundled $(31,32)$. To quantify the uniformity of the LLIA film in large area, we extract the height profiles (Fig. S4) from the AFM image, use it to calibrate the contrast of the OM image, and obtain the height mapping from the OM image (Fig. S5). The height distributions are extracted from both the AFM image (small area) and the OM image (large area) as shown in Fig. 3C. It is observed that both distributions peak at around $2 \mathrm{~nm}$, which corresponds to the thickness of 1-layer of $\mathrm{Ti}_{3} \mathrm{C}_{2} \mathrm{~T}_{\mathrm{x}}$ flakes. The second most significant peak is at around $3.8 \mathrm{~nm}$, which corresponds to the overlapped area of two adjacent flakes (2 layers). These 1-layer and 2- 
layer regions are the key functional components for the electrical conductance, which covers $64 \%$ and $18 \%$ of the film, respectively.

Because of the uniform height distributions and the high 1-layer and 2-layer coverage, the LLIA $\mathrm{Ti}_{3} \mathrm{C}_{2} \mathrm{~T}_{\mathrm{x}}$ films show both high optical transparency and high electrical conductance, making them ideal for the transparent electrodes of EC devices. The optical and electronic properties are evaluated by ultraviolet-visible (UV-vis) spectrophotometry and a four-point probe resistance measurement technique. The UV-vis spectra of these films with different $\mathrm{Ti}_{3} \mathrm{C}_{2} \mathrm{~T}_{\mathrm{x}}$ concentrations (amount of injected $\mathrm{Ti}_{3} \mathrm{C}_{2} \mathrm{~T}_{\mathrm{x}}$ over the total area of the liquid-liquid interface) are presented in Fig. 3D. The transmittance of LLIA $\mathrm{Ti}_{3} \mathrm{C}_{2} \mathrm{~T}_{\mathrm{x}}$ at $550 \mathrm{~nm}$ reaches $96.8 \%$ when the concentration is $1 \mu \mathrm{g}$ $\mathrm{cm}^{-2}$, and decreases steadily to $64.3 \%$ as the concentration increases to $60 \mu \mathrm{g} \mathrm{cm}^{-2}$ (33). The transmittance at $550 \mathrm{~nm}$ versus the sheet resistance $\left(R_{\mathrm{S}}\right)$ of the LLIA films, together with the data from previously reported techniques, are plotted in Fig. 3E. The $R_{\mathrm{s}}$ value of the LLIA $\mathrm{Ti}_{3} \mathrm{C}_{2} \mathrm{~T}_{\mathrm{x}}$ film reaches $1623 \Omega \mathrm{sq}^{-1}$ at a transmittance of $96.9 \%, 210 \Omega \mathrm{sq}^{-1}$ at $94.1 \%$, and $123 \Omega \mathrm{sq}^{-1}$ at $87.8 \%$. Comparing the resistances of materials with the similar transparency, our values are lower than MXene films made by other methods like spin coating (201 $\Omega \mathrm{sq}^{-1}$ at $87 \%$ ), dip coating (4300 $\Omega$ $\mathrm{sq}^{-1}$ at $94 \%$ ), and spray coating (7974 $\Omega \mathrm{sq}^{-1}$ at $82 \%$ ), and also lower than other transparent conductive materials such as graphene, and reduced graphene oxide (see Table $\mathbf{S 1}$ for a summary of different transparent conductive materials) (31, 32, 34-41). Finally, Fig. 3F shows that the LLIA $\mathrm{Ti}_{3} \mathrm{C}_{2} \mathrm{~T}_{\mathrm{x}}$ film can be transferred onto a flexible substrate (e.g. PET) uniformly in large area $(\sim 25$ $\mathrm{cm}^{2}$ ) with very good optical transparency, suitable for transparent conductive films for the proposed EC device structure. 


\section{Fast and high efficiency electrochromism in $\mathrm{MXene/TiO_{2 }}$ heterostructures}

The flexible $\mathrm{TiO}_{2} / \mathrm{Ti}_{3} \mathrm{C}_{2} \mathrm{~T}_{\mathrm{x}}$ heterostructure electrodes are fabricated by transferring LLIA $\mathrm{TiO}_{2}$ films on the $\mathrm{Ti}_{3} \mathrm{C}_{2} \mathrm{~T}_{\mathrm{x}} /$ PET substrates. Because of the well-controlled LLIA process, it is possible to regulate the EC properties simply by the thickness of the $\mathrm{TiO}_{2}$ layer. As shown in Fig. $\mathbf{4 A}, 1$ to 5 layers of the LLIA $\mathrm{TiO}_{2}$ film are transferred sequentially onto a PET substrate in a layer-by-layer fashion. They are almost indistinguishable at the bleach state, when no bias is applied, but become translucent with different opacity at the colored state, when emerged in an electrolyte solution (1M $\mathrm{LiClO}_{4} /$ propylene carbonate $\left.(\mathrm{PC})\right)$ and biased with a constant negative voltage $(-1.6 \mathrm{~V})$. This optical opacity induced by a negative potential is associated with the reduction of $\mathrm{TiO}_{2}$ by counterions $\mathrm{Li}^{+}$and the formation of $\mathrm{Li}_{\mathrm{x}} \mathrm{TiO}_{2}(42)$.

The EC performance of the nm LLIA $\mathrm{TiO}_{2} / \mathrm{Ti}_{3} \mathrm{C}_{2} \mathrm{~T}_{\mathrm{x}}$ heterostructures is much better than previous reports according to the in-situ UV-Vis-NIR spectrophotometry. The measured spectra of the $\mathrm{TiO}_{2} / \mathrm{Ti}_{3} \mathrm{C}_{2} \mathrm{~T}_{\mathrm{x}}$ heterostructures at $0 \mathrm{~V}$ and $-1.6 \mathrm{~V}$ biases are shown in Fig. 4B and Fig. S6, The optical modulation range $\Delta T$ is defined as $\Delta T=T_{\mathrm{b}}-T_{\mathrm{c}}=\exp \left(-\alpha_{\mathrm{b}} L\right)-\exp \left(-\alpha_{\mathrm{c}} L\right)$, where $T_{\mathrm{b}}$ and $T_{\mathrm{c}}$ are the transmittance of the bleach state and the colored state, $\alpha_{\mathrm{b}}$ and $\alpha_{\mathrm{c}}$ represent absorption coefficient of the bleach and the colored state of the LLIA film, and L is the thickness of the film. $\Delta T$ at the wavelength of $550 \mathrm{~nm}$ increases gradually with the layer numbers of the transferred LLIA $\mathrm{TiO}_{2}$ films $(7.19 \%, 12.26 \%, 21.12 \%, 25.60 \%, 32.12 \%, 38.20 \%$, and $41.09 \%$ from 1 to 7 layers) (Table S2). The absorption coefficient change $\Delta \alpha$ can be obtained by $\Delta \alpha=\alpha_{\mathrm{c}}-\alpha_{\mathrm{b}} \approx$ $\left[\ln \left(T_{\mathrm{d}} / T_{\mathrm{b}}\right)\right] / \mathrm{L}$, which is a physical parameter independent of geometries of the film, thus can be used to compare different technologies. $\Delta \alpha$ of the LLIA $\mathrm{TiO}_{2}$ film is extracted to be $0.12 \mathrm{~nm}^{-1}$, which is almost one order of magnitude higher than the previously reported $\mathrm{TiO}_{2}$-based $\mathrm{EC}$ 
materials assembled by other methods (Table S4) (20,43-54), suggesting a very high utilization of $\mathrm{TiO}_{2}$ in the LLIA films during the EC process.

To quantify the utilization rates of both the EC material and the pumped charge, the optical density change $\left(\triangle O D=\log _{10}\left(T_{\mathrm{b}} / T\right)\right)$ as the function of the pumped charge density $(Q$, calculated by an integration of the driving current density over time) during the coloration half-cycle is measured and plotted in Figure 4C. The coloration efficiencies (CE) (55), defined as the slope of

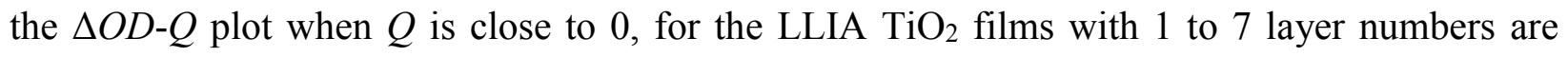
extracted to be 277, 271, 260, 263, 259, 245 and $243 \mathrm{~cm}^{2} \mathrm{C}^{-1}$, respectively (Fig. $4 \mathrm{C}$ and Table S2). These high CE values indicate that small amounts of charge insertion/extraction can result in a large optical modulation, which is a results of high utilization rates of both the EC materials and the pumped charges. High $C E$ also guarantees the long-term electrochemical stability. As expected, the LLIA films shows maintained optical contrast (up to $95 \%$ of its original value) after 500 EC cycles (Fig. S7 and S8). This high cycling stability is essential for practical applications of the EC devices.

The coloration/bleaching time $\tau_{\mathrm{c}} / \tau_{\mathrm{b}}$, another important figure-of-merit for EC materials, defined as the time needed for $90 \%$ of the total optical change, is also investigated on the LLIA $\mathrm{TiO}_{2} / \mathrm{Ti}_{3} \mathrm{C}_{2} \mathrm{~T}_{\mathrm{x}}$ heterostructures. The temporal responses of the transmittance at $550 \mathrm{~nm}$ are measured as the bias is switched between $-1.6 \mathrm{~V}$ and $0 \mathrm{~V}$ periodically (Fig. 4D). The

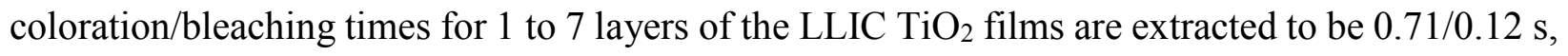
$0.73 / 0.12 \mathrm{~s}, 1.03 / 0.20 \mathrm{~s}, 1.11 / 0.24 \mathrm{~s}, 1.08 / 0.26 \mathrm{~s}, 1.23 / 0.29 \mathrm{~s}$ and $1.63 / 0.38 \mathrm{~s}$ (also summarized in Table S2), which are much shorter than those of reported $\mathrm{TiO}_{2} \mathrm{EC}$ electrode (generally $>10 \mathrm{~s}$ ) and most reported inorganic materials, and comparable to those of organic EC materials (Table S4). 
Ion diffusion process inside the EC material plays a crucial role in the EC performance. To further explore the $\mathrm{Li}^{+}$diffusion behavior of the $\mathrm{LLIA} \mathrm{TiO}_{2}$ films during the EC process, cyclic voltammetry (CV) and electrochemical impedance spectroscopy (EIS) are measured (details are listed in method section). All LLIA films exhibit one pair of redox peaks in their CV curves, corresponding to the reduction and oxidation of $\mathrm{TiO}_{2}$ (Fig. S9). According to the EIS results as shown in Fig. S10 and Table S3, the equivalent series resistance (ESR) does not change much as the $\mathrm{TiO}_{2}$ thickness increases from 1 to 7 layers, and the charge-transfer resistance $\left(R_{\mathrm{ct}}\right)$ only raises from $8.7 \Omega$ to $15.7 \Omega$, indicating that multilayer stacking does not decrease the conductivity and charge-transfer speed significantly at the interface of the $\mathrm{TiO}_{2}$ film and electrolyte.

The apparent ion diffusion coefficient $D$, which represents the kinetics of ion insertion/extraction in the EC film, can be extracted either from the scanning-rate-dependent $\mathrm{CV}$ measurements, or from the Warburg region of the Bode plot obtained from the EIS measurements (see methods for details about the extraction methods of $D$ ) (56). As shown in Fig. 4E, the $D$ values extracted from the CV and from the EIS measurements are $5.05 \times 10^{-14}, 9.63 \times 10^{-14}, 2.68 \times 10^{-13}$, $1.15 \times 10^{-12}, 5.45 \times 10^{-12}, 6.29 \times 10^{-12}$, and $1.10 \times 10^{-11} \mathrm{~cm}^{2} \mathrm{~s}^{-1}$, and $2.75 \times 10^{-12}, 3.94 \times 10^{-12}, 6.59 \times 10^{-12}$, $1.21 \times 10^{-11}, 1.39 \times 10^{-11}, 1.88 \times 10^{-11}, 2.24 \times 10^{-11} \mathrm{~cm}^{2} \mathrm{~s}^{-1}$, respectively, as the number of layer of the $\mathrm{TiO}_{2}$ film increases from 1 to 7 . The positive correlation between $D$ and the layer number can be attributed to the increased electrochemical area of the $\mathrm{LLIA}^{\mathrm{TiO}}{ }_{2}$ film due to its high surface-tovolume ratio, which will be explained later.

To benchmark the overall EC performance, the values of $C E$ and $\tau_{\mathrm{c}}$ of the LLIA $\mathrm{TiO}_{2} / \mathrm{Ti}_{3} \mathrm{C}_{2} \mathrm{~T}_{\mathrm{x}}$ heterostructures as well as previously reported EC materials are summarized in Fig. 4F and Table S4. It is clearly observed that both the $C E$ and the response time of our proposed structures are several times or even one order of magnitude better than both other materials such 
as $\mathrm{WO}_{3}$, and other nanostructured $\mathrm{TiO}_{2}$, including dense films and other $0 \mathrm{D}$ or $1 \mathrm{D}$ nanostructures, and comparable with organic materials. Moreover, LLIA $\mathrm{TiO}_{2} / \mathrm{Ti}_{3} \mathrm{C}_{2} \mathrm{~T}_{\mathrm{x}}$ heterostructures also show a good cycling stability, addressing the ultraviolet/electrochemical decomposition problem of traditional organic materials in applications (18).

We believe that the superiority of the EC performance of the LLIA $\mathrm{TiO}_{2} / \mathrm{Ti}_{3} \mathrm{C}_{2} \mathrm{~T}_{\mathrm{x}}$ heterostructures mainly results from the $2 \mathrm{D}$ nature of the $\mathrm{TiO}_{2}$ flakes as well as the loosely networked structures. To understand this, we propose two possible ion transport pathways (19). The first ion transport pathway is that the $\mathrm{Li}^{+}$ions enters the EC material only at the top surface, and the redoxation deeper into the $\mathrm{EC}$ material is accessed by inter-crystal-lattice diffusion of $\mathrm{Li}^{+}$ ions; whereas in the second ion transport pathway (as illustrated in Fig. $\mathbf{4 G}$ ), $\mathrm{Li}^{+}$ions could travel to all the surfaces of individual EC nanostructures efficiently in the liquid phase, and as a result, the diffusion and the redoxation take place throughout the entire EC nanostructures simultaneously. For dense films, only the first pathway takes place, resulting in very bad coloration efficiency and very slow coloration/bleaching time; while for nanostructured films (including our 2D nanostructures and previously reported 0D or 1D nanostructures), the second pathway, which is more efficient and much faster, starts to play an important role. The higher probability the second pathway takes place in a nanostructured film, the better EC performance it can achieve.

Our experimental results suggest that the second pathway is the dominating $\mathrm{Li}^{+}$ion transport mechanism in the proposed self-assembled $2 \mathrm{D} \mathrm{TiO}_{2}$ films. First, the high $C E$ and its small decrease with the thickness suggest that $\mathrm{Li}^{+}$ions can easily access all the $\mathrm{TiO}_{2}$ flakes regardless of the depth of them from the top surface of the film. Second, the color change time $\tau$ ( $\tau_{\mathrm{c}}$ or $\tau_{\mathrm{b}}$ ) is fast and stays almost the same with different thicknesses. Given that $\tau$ is proportional to the square of the depth of the diffusion, we speculate that the effective diffusion depth is likely 
to be determined by the average thickness of individual $\mathrm{TiO}_{2}$ flakes, rather than the thickness of the assembled $\mathrm{TiO}_{2}$ film. Last, the increasing trend between $D$ and the thickness indicates that it is less likely that the extremely slow inter-nanosheet diffusion is contributed to the measured apparent diffusion coefficient. Instead, $D$ follows a parabolic trend with the thickness (see Fig. S11), or the number of layers, which agrees well if considering the contribution from the electrochemical area $A_{\mathrm{EC}}$ and assuming a linear increase of $A_{\mathrm{EC}}$ with the number of layers, that is, $D \sim\left(A_{\mathrm{EC}} / A\right)^{2} D_{0} \propto N^{2}$, where $A$ is the geometrical area, $D_{0}$ is the intrinsic diffusion coefficient, and $N$ is the number of layers. All these experimental observations can be explained well if the performance is governed by the second ion transport pathway, in which all the surfaces of the 2D $\mathrm{TiO}_{2}$ flakes are interfacing well with the electrolyte, and the actual diffusion length is approximately the thickness of individual $\mathrm{TiO}_{2}$ flakes (Fig. 4G). As a comparison, for 1D or 0D nanostructures, although the ideal surface-to-volume might be even larger, the surfaces may not be fully exposed to the electrolyte because of the denser packing of these nanostructures in a film. Consequently, the $\mathrm{Li}^{+}$ions have to undergo the first pathway in order to access the deeper $\mathrm{EC}$ materials, which tremendously limits the speed and thus reduces the coloration efficiency.

\section{Flexible $\mathrm{MXene} / \mathrm{TiO} \mathrm{O}_{2}$ heterostructure $\mathrm{EC}$ devices for large-area applications}

The overall flexibility of an EC device is determined by the most rigid layer. In our proposed $\mathrm{TiO}_{2} / \mathrm{Ti}_{3} \mathrm{C}_{2} \mathrm{~T}_{\mathrm{x}}$ heterostructure, both the EC layer and the transparent electrode have superior mechanical bendability. To confirm this, bending test is performed on the as-fabricated LLIA electrode. As shown in Fig. 5A, the resistance of the $\mathrm{Ti}_{3} \mathrm{C}_{2} \mathrm{~T}_{\mathrm{x}} / \mathrm{PET}$ film increases by only $6 \%$ after 1000 bending and release cycles at a bending radius of $0.3 \mathrm{~cm}$, whereas the sheet resistance of a commercial ITO/PET film increases quickly by 3 orders of magnitude after 1000 bending cycles even at a much larger bending radius of $1.5 \mathrm{~cm}$. The EC optical switching behaviors of the 
$\mathrm{TiO}_{2} / \mathrm{Ti}_{3} \mathrm{C}_{2} \mathrm{~T}_{\mathrm{x}} / \mathrm{PET}$ film and the $\mathrm{TiO}_{2} / \mathrm{ITO} / \mathrm{PET}$ before and after 1000 bending cycles are also tested (Fig. 5B). $\Delta T$ of the $\mathrm{TiO}_{2} / \mathrm{Ti}_{3} \mathrm{C}_{2} \mathrm{~T}_{\mathrm{x}} / \mathrm{PET}$ electrode remains at $94 \%$ of its original value after 1000 bending cycles. In contrast, $\Delta T$ of the $\mathrm{TiO}_{2} / \mathrm{ITO} / \mathrm{PET}$ electrode drops to about $30 \%$ after 1000 cycles.

Finally, a large-area flexible EC device with a dimension of $30 \mathrm{~cm} \times 20 \mathrm{~cm}$ are demonstrated as an example for practical large-area applications. As shown in Fig. 5C, it is composed of a LLIA $\mathrm{TiO}_{2} / \mathrm{Ti}_{3} \mathrm{C}_{2} \mathrm{~T}_{\mathrm{x}}$ heterostructure on a PET substrate as the EC electrode, another LLIA $\mathrm{Ti}_{3} \mathrm{C}_{2} \mathrm{~T}_{\mathrm{x}} / \mathrm{PET}$ film as the counter electrode, and a $1 \mathrm{M} \mathrm{LiClO}_{4} / \mathrm{PC} / \mathrm{Poly}$ (methyl methacrylate) (PMMA) layer as the electrolyte. Benefit from the exceptional optical memory effect of $\mathrm{TiO}_{2}$ based materials, the EC device can maintain its coloration state after disconnecting from the voltage supply (Fig. 5D and 5E), which is advantageous for energy saving in future applications. The EC device presents a uniform color distribution even in the bending state, which opens up the possibility of scaling up this technology for applications such as flexible displays, smart windows, and other ubiquitous electronics.

\section{Discussion}

In summary, high performance and flexible EC devices are realized based on assembled 2D $\mathrm{TiO}_{2} / \mathrm{Ti}_{3} \mathrm{C}_{2} \mathrm{~T}_{\mathrm{x}}$ heterostructures. This success benefits from several important achievements in this work, including the realization of single crystalline $2 \mathrm{D} \mathrm{TiO}_{2}$ flakes with micrometer-scale sizes and nanometer-scale thicknesses, and the liquid/liquid interfacial self-assembly technique enabled mass production of self-assembled MXene and 2D TMO films with good uniformity. We expect our approach to synthesize $2 \mathrm{D} \mathrm{TiO}_{2}$ crystals to be developed to a general methodology for the synthesis of high-quality 2D MXene derivatives. Also, the self-assembled MXene films could be used as flexible, transparent, and porous electrodes in large-scale electronic, optoelectronic and 
energy-harvesting applications. Our performance test clearly shows that exceptional electrochromic efficiency, fast coloration speed, and good flexibility are achieved simultaneously on the self-assembled 2D TMO/MXene heterostructures based EC devices, which is attributed to the unique electrical, electrochemical, and mechanical properties of the networks of 2D nanostructures. Finally, a large-area flexible electrochromic device is demonstrated, paving the way for integrating electrochromic devices to next-generation flexible and wearable electronics. 


\section{Materials and Methods}

\section{Chemicals}

All the starting materials are available commercially and used as received. Polyethylene terephthalate (PET) was rinsed sequentially in the baths of deionized water, acetone, and isopropanol. $\mathrm{Ti}_{3} \mathrm{AlC}_{2}$ (MAX-Phase, purchased from 11 Technology Co. Ltd), lithium fluoride (LiF, Alfa Aesar, 99.99\%), hydrochloric acid (HCl, Fisher Chemical, 6M), 1-hexene (Acros Organics, 99\%), isopropyl alcohol (IPA, Fisher Chemical, 99\%), propylene carbonate (PC, Alfa Aesar, 99\%), lithium perchlorate $\left(\mathrm{LiClO}_{4}\right.$, Acros Organics, 99+\%), poly(methyl methacrylate) (PMMA, ACROS Organics, M.W. 35000) were utilized without initial treatments.

\section{Synthesis and interfacial assembly of $\mathrm{Ti}_{3} \mathrm{C}_{2} \mathrm{~T}_{\mathrm{x}}$ and $2 \mathrm{D} \mathrm{TiO}_{2}$ films}

$\mathrm{Ti}_{3} \mathrm{AlC}_{2}$ etching was performed following Gogosti's work(23) to prepare $2 \mathrm{D} \mathrm{Ti}_{3} \mathrm{C}_{2} \mathrm{~T}_{\mathrm{x}}$. Briefly, 1.6 g lithium fluoride was dissolved into $5 \mathrm{~mL}$ of DI water with $15 \mathrm{~mL} 12 \mathrm{M}$ hydrochloric acid solution in plastic bottle as the etchant solution. Then $1 \mathrm{~g} \mathrm{Ti}_{3} \mathrm{AlC}_{2}$ (MAX phase) powders was gradually added to the etchant solution within 5 minutes and the reaction is maintained with stirring the reactants at $40^{\circ} \mathrm{C}$ in a silicon oil bath for $24 \mathrm{~h}$. Etched MXene was washed with DI water, and isolated by centrifugation at $3500 \mathrm{rpm}$ for 5 minutes. Washing was repeated several times until a stable dark supernatant solution of $\mathrm{Ti}_{3} \mathrm{C}_{2} \mathrm{~T}_{\mathrm{x}}$ flakes with a $\mathrm{pH}$ value of around 6 was obtained. The solution was subsequently centrifuged for 30 minutes at $3500 \mathrm{rpm}$, after which a dark sediment of $\mathrm{Ti}_{3} \mathrm{C}_{2} \mathrm{~T}_{\mathrm{x}}$ was observed and then collected.

To obtaine the $\mathrm{TiO}_{2}$ aerogel, the $\mathrm{Ti}_{3} \mathrm{C}_{2} \mathrm{~T}_{\mathrm{x}}$ gel was diluted to $0.2 \mathrm{mg} / \mathrm{ml}$ with DI water, then the solution were freeze dried at $-47^{\circ} \mathrm{C}$ for days to form an aerogel. Next, the $\mathrm{Ti}_{3} \mathrm{C}_{2} \mathrm{~T}_{\mathrm{x}}$ aerogel was put in a ceramic boat and annealed at the temperature of $400^{\circ} \mathrm{C}$ for $50 \mathrm{~h}$ with the heating rate of $1^{\circ} \mathrm{C} / \mathrm{min}$. 
To assemble the $\mathrm{Ti}_{3} \mathrm{C}_{2} \mathrm{~T}_{\mathrm{x}}$ flakes into a continuous film, the $\mathrm{Ti}_{3} \mathrm{C}_{2} \mathrm{~T}_{\mathrm{x}}$ aerogel was dispersed in an IPA solution $(2 \mathrm{mg} / \mathrm{ml}$ ) by sonicating for 30 minutes. Hexane (with a height of $\sim 2 \mathrm{~cm}$ ) was carefully poured on the top of DI water (with a height of $\sim 6 \mathrm{~cm}$ ) to set up an interface between these two liquids. Then, the $\mathrm{Ti}_{3} \mathrm{C}_{2} \mathrm{~T}_{\mathrm{x}} / \mathrm{IPA}$ dispersion was slowly injected near the interface to form a continuous film. After removing the top hexane layer, the self-assembly film was transferred onto a substrate and annealed at $90^{\circ} \mathrm{C}$ in vacuum for $50 \mathrm{~h}(<0.05 \mathrm{MPa})$.

The assembly for the $\mathrm{TiO}_{2}$ films is similar to the $\mathrm{Ti}_{3} \mathrm{C}_{2} \mathrm{~T}_{\mathrm{x}}$ assembly process. For multilayered $\mathrm{TiO}_{2}$, the transferred films were dried at $60{ }^{\circ} \mathrm{C}$ in vacuum for $1 \mathrm{~h}$, and then treated with oxygen plasma (the oxygen gas flow rate is $50 \mathrm{SCCM}$, and power is $100 \mathrm{~W}$ ) for $30 \mathrm{~s}$ before each cycle, then the $\mathrm{TiO}_{2} / \mathrm{Ti}_{3} \mathrm{C}_{2} \mathrm{~T}_{\mathrm{x}}$ heterostructures were annealed at $90^{\circ} \mathrm{C}$ in vacuum $(<0.05$ $\mathrm{MPa}$ ) for $50 \mathrm{~h}$ before use.

\section{Assembly of the Electrochromic device}

The electrolyte gel was obtained by mixing $1 \mathrm{M} \mathrm{LiClO}_{4}$ in a PC solution and $20 \mathrm{wt} \%$ PMMA (relative to the $\mathrm{LiClO}_{4} / \mathrm{PC}$ solution). The $\mathrm{EC}$ devices were fabricated by hot pressing the electrolyte gel sandwiched by the $\mathrm{TiO}_{2} / \mathrm{Ti}_{3} \mathrm{C}_{2} \mathrm{~T}_{\mathrm{x}} / \mathrm{PET}$ electrodes and the $\mathrm{Ti}_{3} \mathrm{C}_{2} \mathrm{~T}_{\mathrm{x}} / \mathrm{PET}$ counter electrode with a scotch tape spacer (with the thickness of $1 \mathrm{~mm}$ ) at $60^{\circ} \mathrm{C}$.

\section{Material characterization}

The X-ray diffraction (XRD) patterns were measured using an X-ray diffractometer (Bruker AXS $\mathrm{X} 8$ Proteum-R instrument) with the radiation at $40 \mathrm{kV}$ and $200 \mathrm{~mA}$. Raman spectroscopy measurements were performed on a Renishaw inVia Raman microscope equipped with a $532 \mathrm{~nm}$ laser line (The laser power on the samples is about $1.6 \mathrm{~mW}$ ). All the spectra in comparison were taken under the same conditions. Transmission electron microscopy (TEM) measurements were performed on a FEI Tecnai Osiris TEM. Selected area electron diffraction (SAED) was measured 
on a JEOL 2100 TEM. The AFM measurements were conducted on a Bruker Dimension system. X-ray photoelectron spectroscopy (XPS) measurements were performed using a PHI Versaprobe II. The UV-vis spectroscopy was carried out using a Agilent CARY 5000.

\section{Electrochemical measurements and parameter extraction}

Electrochemical measurements were carried out in a PC solution containing $1 \mathrm{M} \mathrm{\textrm {LiClO } _ { 4 }}$ electrolyte using three-electrode electrochemical cells with the $\mathrm{TiO}_{2} / \mathrm{Ti}_{3} \mathrm{C}_{2} \mathrm{~T}_{\mathrm{x}} / \mathrm{PET}$ films as the working electrodes, a platinum plate as the counter electrode, and a freshly prepared $\mathrm{Ag} / \mathrm{Ag}^{+}$as the pseudo-reference electrode (calibrated by ferrocene). Electrochemical impedance spectroscopy (EIS) and cycle voltammetry (CV) were conducted by an electrochemical workstation (Bio-logic SAS, VSP-300) over a frequency range of $100 \mathrm{mHz}-1000 \mathrm{KHz}$.

The measured EIS spectra was fitted with a circuit model illustrated in Fig. S10. As shown in Fig. S10, the Nyquist plot of all films is composed of three parts: an equivalent series resistance $(E S R)$ in series with a semicircle consisting of a non-faradaic double layer capacitance $\left(C_{\mathrm{dl}}\right)$ and a charge-transfer resistance $\left(R_{\mathrm{ct}}\right)$ at high frequency; a $45^{\circ}$ linear region representing the Warburg element $(W)$, which captures the ion diffusion process at medium frequency; and a line related to the capacitive charging behavior of the pseudo-capacitance $\left(C_{\mathrm{p}}\right)$ of $\mathrm{TiO}_{2}$ film and its bulk resistance $\left(R_{\mathrm{p}}\right)$ at low frequency.

The apparent ion diffusion coefficient $D$ can be extracted from both the EIS measurements and the $\mathrm{CV}$ measurements. In the first method, $D_{\text {EIS }}$ can be calculated from the Warburg region according to equations (1) and (2) $(56,57)$ :

$$
\begin{aligned}
& Z_{\mathrm{w}}=\sigma \omega^{-1 / 2} \\
& D_{\mathrm{EIS}}=R^{2} T^{2} /\left(2 A^{2} n^{4} F^{4} C^{2} \sigma^{2}\right)
\end{aligned}
$$


where $\sigma$ is the slope of $Z_{\mathrm{w}}$ against $\omega^{-1 / 2}, R$ is the gas constant, $T$ is the absolute temperature, $A$ is the effective working area (geometrical area), $n$ is the number of electrons involved in the electrochemical reaction, $F$ and $C$ are the Faraday constant and the molar concentration of $\mathrm{Li}^{+}$ions.

In the second method, the apparent ion diffusion coefficients $D_{\mathrm{CV}}$ can be calculated by:(58)

$i_{\mathrm{p}}=2.687 \times 10^{5} \times n^{3 / 2} \times D_{\mathrm{Cv}}{ }^{1 / 2} \times C \times A \times v^{1 / 2}$

where $v$ represents the potential sweeping rate, $i_{\mathrm{p}}$ represents the peak current density. 


\section{References}

1. D. R. Rosseinsky, R. J. Mortimer, Electrochromic Systems and the Prospects for Devices. Adv. Mater. 13, 783-793 (2001).

2. P. R. Somani, S. Radhakrishnan, Electrochromic materials and devices: present and future. Mater. Chem. Phys. 77, 117-133 (2003).

3. S. Cong, Y. Tian, Q. Li, Z. Zhao, F. Geng, Single-Crystalline Tungsten Oxide Quantum Dots for Fast Pseudocapacitor and Electrochromic Applications. Adv. Mater. 26, 4260-4267 (2014).

4. R. J. Mortimer, A. L. Dyer, J. R. Reynolds, Electrochromic organic and polymeric materials for display applications. Displays. 27, 2-18 (2006).

5. S. Zhang, S. Cao, T. Zhang, A. Fisher, J. Y. Lee, $\mathrm{Al}^{3+}$ intercalation/de-intercalation-enabled dual-band electrochromic smart windows with a high optical modulation, quick response and long cycle life. Energy Environ. Sci. 11, 2884-2892 (2018).

6. C. Yan, W. Kang, J. Wang, M. Cui, X. Wang, C. Y. Foo, K. J. Chee, P. S. Lee, Stretchable and Wearable Electrochromic Devices. ACS Nano. 8, 316-322 (2014).

7. R. T. Wen, C. G. Granqvist, G. A. Niklasson, Eliminating degradation and uncovering iontrapping dynamics in electrochromic $\mathrm{WO}_{3}$ thin films. Nat. Mater. 14, 996-1001 (2015).

8. Z. Fu, N. Wang, D. Legut, C. Si, Q. Zhang, S. Du, T. C. Germann, J. S. Francisco, R. Zhang, Rational Design of Flexible Two-Dimensional MXenes with Multiple Functionalities. Chem. Rev. 119, 11980-12031 (2019).

9. J. Chen, Q. Huang, H. Huang, L. Mao, M. Liu, X. Zhang, Y. Wei, Recent progress and advances in the environmental applications of MXene related materials. Nanoscale. 12, 3574-3592 (2020).

10. A. Shahzad, K. Rasool, M. Nawaz, W. Miran, J. Jang, M. Moztahida, K. A. Mahmoud, D. S. Lee, Heterostructural $\mathrm{TiO}_{2} / \mathrm{Ti}_{3} \mathrm{C}_{2} \mathrm{~T}_{\mathrm{x}}$ (MXene) for photocatalytic degradation of antiepileptic drug carbamazepine. Chem. Eng. J. 349, 748-755 (2018).

11. Y. Dong, Z. S. Wu, S. Zheng, X. Wang, J. Qin, S. Wang, X. Shi, X. Bao, $\mathrm{Ti}_{3} \mathrm{C}_{2} \mathrm{MXene}^{-}$ Derived Sodium/Potassium Titanate Nanoribbons for High-Performance Sodium/Potassium Ion Batteries with Enhanced Capacities. ACS Nano. 11, 4792-4800 (2017).

12. J. Pang, R. G. Mendes, A. Bachmatiuk, L. Zhao, H. Q. Ta, T. Gemming, H. Liu, Z. Liu, M. H. Rummeli, Applications of 2D MXenes in energy conversion and storage systems. Chem. Soc. Rev. 48, 72-133 (2019).

13. G. Cai, J. H. Ciou, Y. Liu, Y. Jiang, P. S. Lee, Leaf-inspired multiresponsive MXene-based actuator for programmable smart devices. Sci. Adv. 5, eaaw7956 (2019).

14. P. Salles, D. Pinto, K. Hantanasirisakul, K. Maleski, C. E. Shuck, Y. Gogotsi, Electrochromic Effect in Titanium Carbide MXene Thin Films Produced by Dip-Coating. Adv. Funct. Mater. 29, 1809223 (2019).

15. C. Wang, M. Shim, P. Guyot-Sionnest, Electrochromic Nanocrystal Quantum Dots. Science. 291, 2390-2392 (2001).

16. J. Z. Chen, W. Y. Ko, Y. C. Yen, P. H. Chen, K. J. Lin, Hydrothermally Processed $\mathrm{TiO}_{2}$ Nanowire Electrodes with Antireflective and Electrochromic Properties. ACS Nano. 6, 6633-6639 (2012).

17. Y. C. Nah, A. Ghicov, D. Kim, S. Berger, P. Schmuki, $\mathrm{TiO}_{2}-\mathrm{WO}_{3}$ Composite Nanotubes by Alloy Anodization: Growth and Enhanced Electrochromic Properties. J. Am. Chem. Soc. 130, 16154-16155 (2008).

18. J. Jensen, M. V. Madsen, F. C. Krebs, Photochemical stability of electrochromic polymers 
and devices. J. Mater. Chem. C. 1, 4826-4835 (2013).

19. C. Wang, M. Shim, P. Guyot-Sionnest, Electrochromic Nanocrystal Quantum Dots. Science. 291, 2390-2392 (2001).

20. A. Azam, J. Kim, J. Park, T. G. Novak, A. P. Tiwari, S. H. Song, B. Kim, S. Jeon, TwoDimensional $\mathrm{WO}_{3}$ Nanosheets Chemically Converted from Layered $\mathrm{WS}_{2}$ for HighPerformance Electrochromic Devices. Nano Lett. 18, 5646-5651 (2018).

21. K. Li, Q. Zhang, H. Wang, Y. Li, Lightweight, highly bendable and foldable electrochromic films based on all-solution-processed bilayer nanowire networks. J. Mater. Chem. C. 4, 5849-5857 (2016).

22. L. Liang, J. Zhang, Y. Zhou, J. Xie, X. Zhang, M. Guan, B. Pan, Y. Xie, High-performance flexible electrochromic device based on facile semiconductor-to-metal transition realized by $\mathrm{WO}_{3} \cdot 2 \mathrm{H}_{2} \mathrm{O}$ ultrathin nanosheets. Sci. Rep. 3 (2013).

23. M. Alhabeb, K. Maleski, B. Anasori, P. Lelyukh, L. Clark, S. Sin, Y. Gogotsi, Guidelines for Synthesis and Processing of Two-Dimensional Titanium Carbide $\left(\mathrm{Ti}_{3} \mathrm{C}_{2} \mathrm{~T}_{\mathrm{x}} \mathrm{MXene}\right)$. Chem. Mater. 29, 7633-7644 (2017).

24. Z. S. Khalifa, H. Lin, S. Ismat Shah, Structural and electrochromic properties of $\mathrm{TiO}_{2}$ thin films prepared by metallorganic chemical vapor deposition. Thin Solid Films. 518, 54575462 (2010).

25. R. van de Krol, A. Goossens, E. A. Meulenkamp, In Situ X $\square$ Ray Diffraction of Lithium Intercalation in Nanostructured and Thin Film Anatase $\mathrm{TiO}_{2}$. J. Electrochem. Soc. 146, 3150 (1999).

26. O. Khatim, M. Amamra, K. Chhor, A. M. T. Bell, D. Novikov, D. Vrel, A. Kanaev, Amorphous-anatase phase transition in single immobilized $\mathrm{TiO}_{2}$ nanoparticles. Chem. Phys. Lett. 558, 53-56 (2013).

27. X. T. Gao, Y. Xie, X. D. Zhu, K. N. Sun, X. M. Xie, Y. T. Liu, J. Y. Yu, B. Ding, Ultrathin MXene Nanosheets Decorated with $\mathrm{TiO}_{2}$ Quantum Dots as an Efficient Sulfur Host toward Fast and Stable Li-S Batteries. Small. 14, 1802443 (2018).

28. J. Cao, T. Li, H. Gao, Y. Lin, X. Wang, H. Wang, T. Palacios, X. Ling, Realization of 2D crystalline metal nitrides via selective atomic substitution. Sci. Adv. 6, eaax8784 (2020).

29. X. Yu, M. S. Prévot, N. Guijarro, K. Sivula, Self-assembled 2D $\mathrm{WSe}_{2}$ thin films for photoelectrochemical hydrogen production. Nat. Commun. 6, 7596 (2015).

30. C. V. Sternling, L. E. Scriven, Interfacial turbulence: Hydrodynamic instability and the marangoni effect. AIChE J. 5, 514-523 (1959).

31. C. Zhang, B. Anasori, A. Seral $\square$ Ascaso, S. H. Park, N. McEvoy, A. Shmeliov, G. S. Duesberg, J. N. Coleman, Y. Gogotsi, V. Nicolosi, Transparent, Flexible, and Conductive 2D Titanium Carbide (MXene) Films with High Volumetric Capacitance. Adv. Mater. 29, 1702678 (2017).

32. K. Hantanasirisakul, M. Q. Zhao, P. Urbankowski, J. Halim, B. Anasori, S. Kota, C. E. Ren, M. W. Barsoum, Y. Gogotsi, Fabrication of $\mathrm{Ti}_{3} \mathrm{C}_{2} \mathrm{~T}_{\mathrm{x}}$ MXene Transparent Thin Films with Tunable Optoelectronic Properties. Adv. Electron. Mater. 2, 1600050 (2016).

33. X. Li, T. Yang, Y. Yang, J. Zhu, L. Li, F. E. Alam, X. Li, K. Wang, H. Cheng, C. T. Lin, Y. Fang, H. Zhu, Large-Area Ultrathin Graphene Films by Single-Step Marangoni SelfAssembly for Highly Sensitive Strain Sensing Application. Adv. Funct. Mater. 26, 13221329 (2016).

34. K. Min, T. H. Han, J. Kim, J. Jung, C. Jung, S. M. Hong, C. M. Koo, A facile route to fabricate stable reduced graphene oxide dispersions in various media and their transparent 
conductive thin films. J. Colloid Interface Sci. 383, 36-42 (2012).

35. G. Ying, A. D. Dillon, A. T. Fafarman, M. W. Barsoum, Transparent, conductive solution processed spincast 2D Ti $2 \mathrm{CT}_{\mathrm{x}}$ (MXene) films. Mater. Res. Lett. 5, 391-398 (2017).

36. M. Mariano, O. Mashtalir, F. Q. Antonio, W. H. Ryu, B. Deng, F. Xia, Y. Gogotsi, A. D. Taylor, Solution-processed titanium carbide MXene films examined as highly transparent conductors. Nanoscale. 8, 16371-16378 (2016).

37. G.-M. Weng, J. Li, M. Alhabeb, C. Karpovich, H. Wang, J. Lipton, K. Maleski, J. Kong, E. Shaulsky, M. Elimelech, Y. Gogotsi, A. D. Taylor, Layer-by-Layer Assembly of CrossFunctional Semi-transparent MXene-Carbon Nanotubes Composite Films for NextGeneration Electromagnetic Interference Shielding. Adv. Funct. Mater. 28, 1803360 (2018).

38. S. J. Kim, J. Choi, K. Maleski, K. Hantanasirisakul, H. T. Jung, Y. Gogotsi, C. W. Ahn, Interfacial Assembly of Ultrathin, Functional MXene Films. ACS Appl. Mater. Interfaces. 11, 32320-32327 (2019).

39. C. Zhang, V. Nicolosi, Graphene and MXene-based transparent conductive electrodes and supercapacitors. Energy Storage Mater. 16, 102-125 (2019).

40. G. Ying, S. Kota, A. D. Dillon, A. T. Fafarman, M. W. Barsoum, Conductive transparent $\mathrm{V}_{2} \mathrm{CT}_{\mathrm{x}}$ (MXene) films. FlatChem. 8, 25-30 (2018).

41. P. Salles, E. Quain, N. Kurra, A. Sarycheva, Y. Gogotsi, Automated Scalpel Patterning of Solution Processed Thin Films for Fabrication of Transparent MXene Microsupercapacitors. Small. 14, 1802864 (2018).

42. A. Ghicov, H. Tsuchiya, R. Hahn, J. M. Macak, A. G. Muñoz, P. Schmuki, $\mathrm{TiO}_{2}$ nanotubes: $\mathrm{H}^{+}$insertion and strong electrochromic effects. Electrochem. Commun. 8, 528-532 (2006).

43. J. Z. Chen, W. Y. Ko, Y. C. Yen, P. H. Chen, K. J. Lin, Hydrothermally Processed $\mathrm{TiO}_{2}$ Nanowire Electrodes with Antireflective and Electrochromic Properties. ACS Nano. 6, 6633-6639 (2012).

44. N. N. Dinh, N. Th. T. Oanh, P. D. Long, M. C. Bernard, A. H. Goff, Electrochromic properties of $\mathrm{TiO}_{2}$ anatase thin films prepared by a dipping sol-gel method. Thin Solid Films. 423, 70-76 (2003).

45. Z. Tebby, O. Babot, T. Toupance, D. H. Park, G. Campet, M. H. Delville, Low-Temperature UV-Processing of Nanocrystalline Nanoporous Thin $\mathrm{TiO}_{2}$ Films: An Original Route toward Plastic Electrochromic Systems. Chem. Mater. 20, 7260-7267 (2008).

46. Y. Chen, X. Li, Z. Bi, X. He, G. Li, X. Xu, X. Gao, Design and construction of hierarchical $\mathrm{TiO}_{2}$ nanorod arrays by combining layer-by-layer and hydrothermal crystallization techniques for electrochromic application. Appl. Surf. Sci. 440, 217-223 (2018).

47. R. A. Patil, R. S. Devan, Y. Liou, Y. R. Ma, Efficient electrochromic smart windows of onedimensional pure brookite $\mathrm{TiO}_{2}$ nanoneedles. Sol. Energy Mater. Sol. Cells. 147, 240-245 (2016).

48. Y. Chen, X. Li, Z. Bi, X. He, X. Xu, X. Gao, Core-Shell Nanorod Arrays of Crystalline/Amorphous $\mathrm{TiO}_{2}$ Constructed by Layer-by-Layer Method for HighPerformance Electrochromic Electrodes. Electrochim. Acta. 251, 546-553 (2017).

49. Y. Alesanco, J. Palenzuela, R. Tena-Zaera, G. Cabañero, H. Grande, B. Herbig, A. Schmitt, M. Schott, U. Posset, A. Guerfi, M. Dontigny, K. Zaghib, A. Viñuales, Plastic electrochromic devices based on viologen-modified $\mathrm{TiO}_{2}$ films prepared at low temperature. Sol. Energy Mater. Sol. Cells. 157, 624-635 (2016).

50. R. Li, K. Li, G. Wang, L. Li, Q. Zhang, J. Yan, Y. Chen, Q. Zhang, C. Hou, Y. Li, H. Wang, Ion-Transport Design for High-Performance $\mathrm{Na}^{+}$-Based Electrochromics. ACS Nano. 12, 
3759-3768 (2018).

51. J. L. Wang, Y. R. Lu, H. H. Li, J. W. Liu, S. H. Yu, Large Area Co-Assembly of Nanowires for Flexible Transparent Smart Windows. J. Am. Chem. Soc. 139, 9921-9926 (2017).

52. Q. Zhang, C. Y. Tsai, L. J. Li, D. J. Liaw, Colorless-to-colorful switching electrochromic polyimides with very high contrast ratio. Nat. Commun. 10, 1239 (2019).

53. E. Hwang, S. Seo, S. Bak, H. Lee, M. Min, H. Lee, An Electrolyte-Free Flexible Electrochromic Device Using Electrostatically Strong Graphene Quantum Dot-Viologen Nanocomposites. Adv. Mater. 26, 5129-5136 (2014).

54. S. Cao, S. Zhang, T. Zhang, J. Y. Lee, Fluoride-Assisted Synthesis of Plasmonic Colloidal Ta-Doped $\mathrm{TiO}_{2}$ Nanocrystals for Near-Infrared and Visible-Light Selective Electrochromic Modulation. Chem. Mater. 30, 4838-4846 (2018).

55. S. H. Lee, H. M. Cheong, C. E. Tracy, A. Mascarenhas, A. W. Czanderna, S. K. Deb, Electrochromic coloration efficiency of a- $\mathrm{WO}_{3}-\mathrm{y}$ thin films as a function of oxygen deficiency. Appl. Phys. Lett. 75, 1541-1543 (1999).

56. X. H. Rui, N. Ding, J. Liu, C. Li, C. H. Chen, Analysis of the chemical diffusion coefficient of lithium ions in $\mathrm{Li}_{3} \mathrm{~V}_{2}\left(\mathrm{PO}_{4}\right)_{3}$ cathode material. Electrochim. Acta. 55, 2384-2390 (2010).

57. E. Pehlivan, G. A. Niklasson, C. G. Granqvist, P. Georén, Ageing of electrochromic $\mathrm{WO}_{3}$ coatings characterized by electrochemical impedance spectroscopy. Phys. Status Solidi A. 207, 1772-1776 (2010).

58. S. B. Tang, M. O. Lai, L. Lu, Study on $\mathrm{Li}^{+}$-ion diffusion in nano-crystalline $\mathrm{LiMn}_{2} \mathrm{O}_{4}$ thin film cathode grown by pulsed laser deposition using CV, EIS and PITT techniques. Mater. Chem. Phys. 111, 149-153 (2008).

\section{Acknowledgments}

Author contributions: R. L. and X. M. performed most of experiments. R. L., X. M., X. Z. and L. W. prepared the samples, J. L., J. C., H. G. and T. L. characterized the samples. G. W., C. H. and Y. L. analyzed the data, Q. Z., R. L., Y. L., Y. L., H. W. and X. L. designed experiments. All authors discussed the results and commented on the manuscript.

Funding: X. L., J. C., T. L. and T. P. acknowledge the support from Semiconductor Research Corporation (SRC). X. L. acknowledge the membership of the Photonics Centers at Boston University. H. W. and R. L. acknowledge the financial support of the Natural Science Foundation of China (Grant No.51972054), Fundamental Research Funds for the Central Universities (18D110308). R. L. acknowledge the support of Graduate Student Innovation Fund of Donghua University (CUSF-DH-D-2019002).

Competing interests: The authors declare that they have no competing interests.

Data and materials availability: All data needed to evaluate the conclusions in the paper are present in the paper and/or the Supplementary Materials. Additional data related to this paper may be requested from the authors. 
Figures and Tables
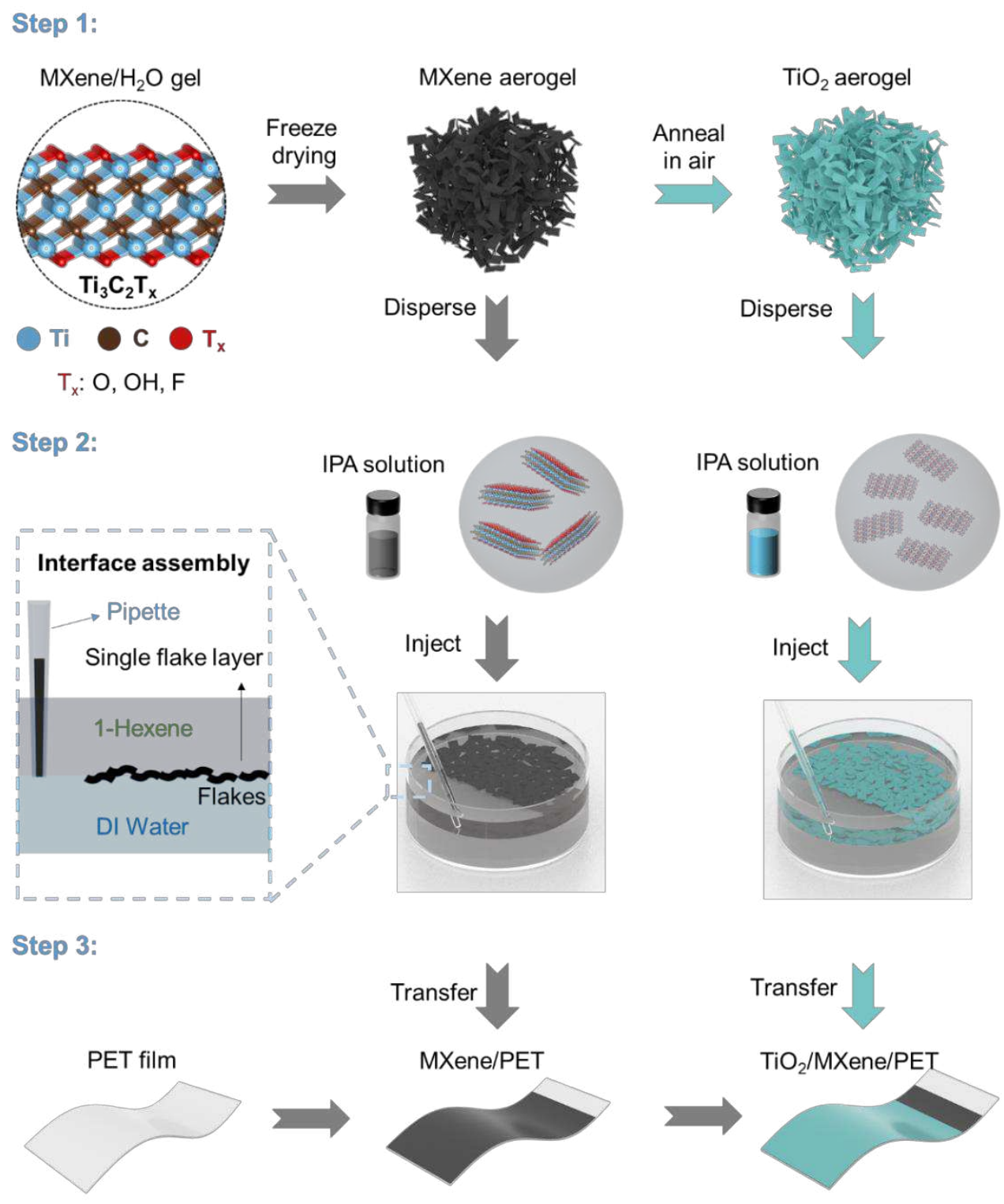

Fig. 1. Fabrication process of $\mathrm{TiO}_{2} / \mathrm{Ti}_{3} \mathrm{C}_{2} \mathrm{~T}_{\mathbf{x}}$ heterostructure on a flexible substrate. Step 1: MXene $\left(\mathrm{Ti}_{3} \mathrm{C}_{2} \mathrm{~T}_{\mathrm{x}}\right)$ aerogel is obtained by freeze drying of the $\mathrm{Ti}_{3} \mathrm{C}_{2} \mathrm{~T}_{\mathrm{x}}$ nanosheets dispersion and the derived $\mathrm{TiO}_{2}$ aerogel is obtained by annealing the $\mathrm{MXene}$ aerogel in air at $400^{\circ} \mathrm{C}$. Step 2: $\mathrm{Ti}_{3} \mathrm{C}_{2} \mathrm{~T}_{\mathrm{x}}$ and $\mathrm{TiO}_{2} 2 \mathrm{D}$ nanosheets are dispersed respectively in IPA, injected into the interface between hexene and DI water, and self-assembled into nanometer-thick $\mathrm{Ti}_{3} \mathrm{C}_{2} \mathrm{~T}_{\mathrm{x}}$ and $\mathrm{TiO}_{2}$ films. Step 3: the thin films are transferred onto a flexible substrate (e.g. PET) in a layer-by-layer fashion to realize the $\mathrm{TiO}_{2} / \mathrm{MXene}$ heterostructure, where the $\mathrm{TiO}_{2}$ layer serves as the electrochromic component, and the MXene layer serves as the transparent electrode. 
A

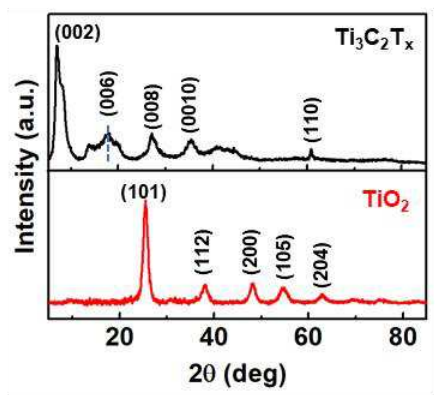

D

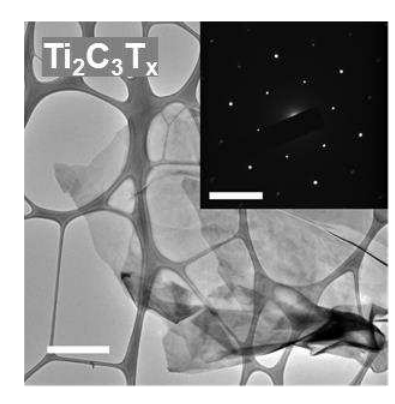

B

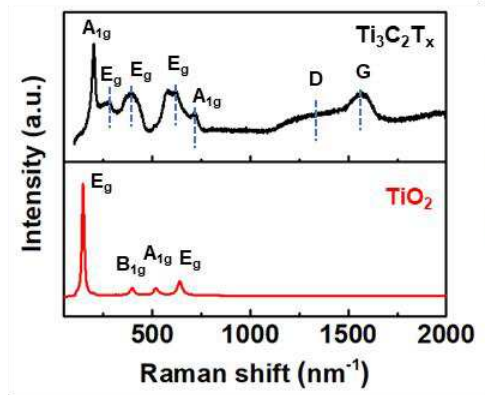

E

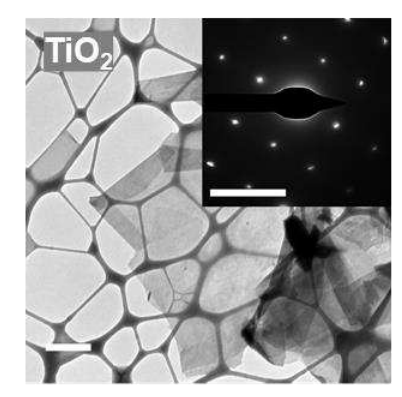

C

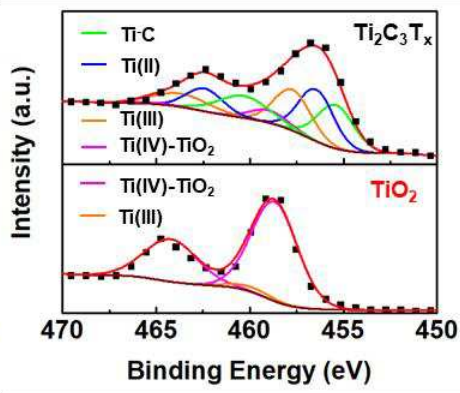

$\mathbf{F}$

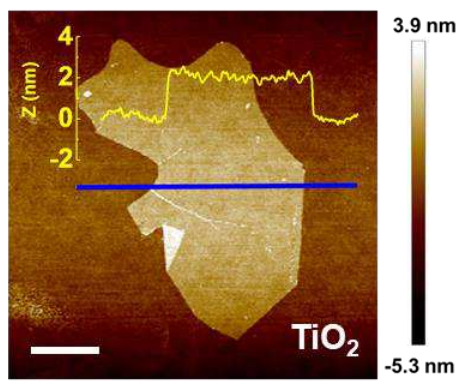

Fig. 2. Conversion of $\mathrm{Ti}_{3} \mathrm{C}_{2} \mathrm{~T}_{\mathbf{x}}$ into $2 \mathrm{D} \mathrm{TiO}_{2}$ flakes. (A) XRD patterns and (B) Raman spectra of the $\mathrm{Ti}_{3} \mathrm{C}_{2} \mathrm{~T}_{\mathrm{x}}$ before and after annealing at $400^{\circ} \mathrm{C}$ for $50 \mathrm{~h}$. (C) XPS spectra of the $\mathrm{Ti}_{3} \mathrm{C}_{2} \mathrm{~T}_{\mathrm{x}}$ and the derived $\mathrm{TiO}_{2}$. TEM images of $(\mathrm{E}) \mathrm{Ti}_{3} \mathrm{C}_{2} \mathrm{~T}_{\mathrm{x}}$ and $(\mathrm{F})$ derived $\mathrm{TiO}_{2}$ flakes on a TEM grid (scale bar: 1 $\mu \mathrm{m}$ ). Insets: SEAD patterns of $\mathrm{Ti}_{3} \mathrm{C}_{2} \mathrm{~T}_{\mathrm{x}}$ and derived $\mathrm{TiO}_{2}$ flakes (scale bar: $5 \mathrm{~nm}^{-1}$ ); (F) AFM image and height profile of a derived $\mathrm{TiO}_{2}$ flake on a $\mathrm{SiO}_{2} / \mathrm{Si}$ substrate (scale bar: $2 \mu \mathrm{m}$ ). 
A

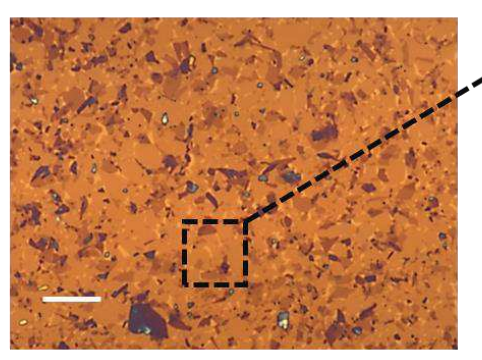

D

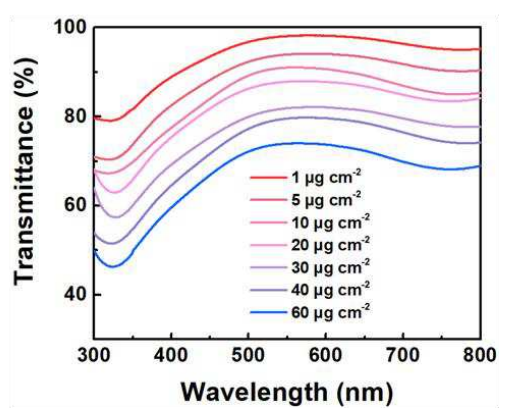

B

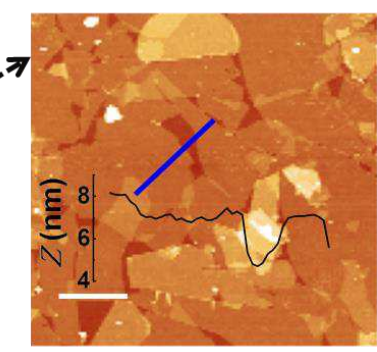

E
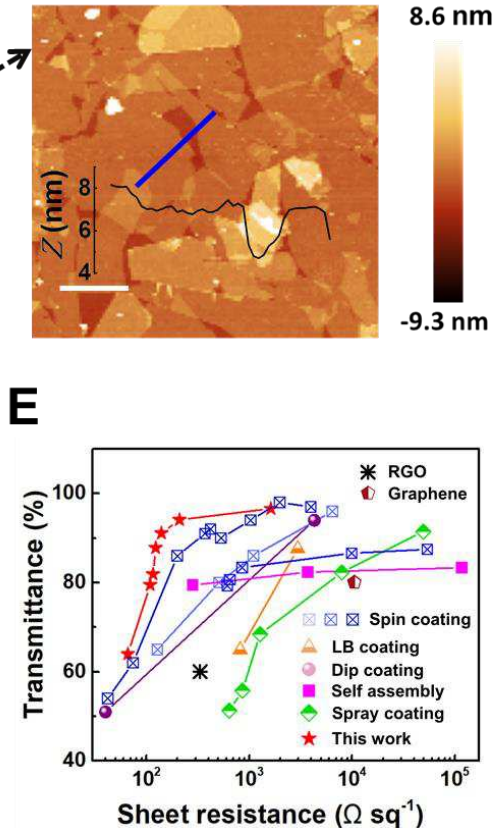

C

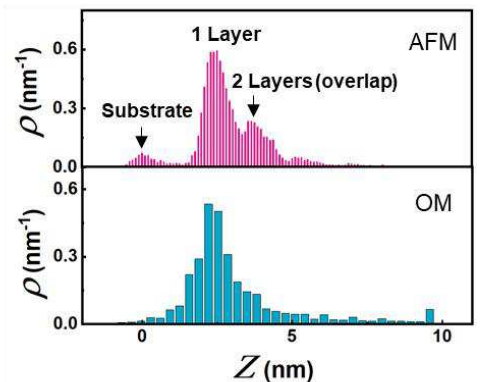

$\mathbf{F}$

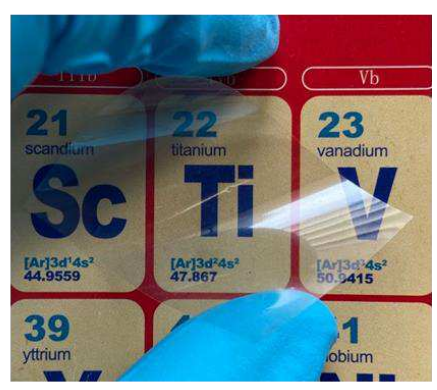

Fig. 3. Characterization of the self-assembled $\mathrm{Ti}_{3} \mathrm{C}_{2} \mathrm{~T}_{\mathbf{x}}$ thin film as a transparent electrode. (A) $\mathrm{OM}$ image of the assembled $\mathrm{Ti}_{3} \mathrm{C}_{2} \mathrm{~T}_{\mathrm{x}}$ thin film (scale bar: $10 \mu \mathrm{m}$ ). (B) AFM image and the height profile of the assembled $\mathrm{Ti}_{3} \mathrm{C}_{2} \mathrm{~T}_{\mathrm{x}}$ thin film in corresponding area marked in (A) (scale bar: $2 \mu \mathrm{m}$ ). (C) Height distributions extracted from the AFM image (top) and the OM image (bottom); the $y$-axes are probability density, namely, frequency per unit height; (D) Transmittance spectra of $\mathrm{Ti}_{3} \mathrm{C}_{2} \mathrm{~T}_{\mathrm{x}}$ films with various concentrations of injected $\mathrm{Ti}_{3} \mathrm{C}_{2} \mathrm{~T}_{\mathrm{x}}$; (E) Transmittance at $550 \mathrm{~nm}$ as a function of sheet resistance for the $\mathrm{Ti}_{3} \mathrm{C}_{2} \mathrm{~T}_{\mathrm{x}}$ films and data from previously reported transparent electrode technologies; (F) Photograph of a $\mathrm{Ti}_{3} \mathrm{C}_{2} \mathrm{Tx}$ film deposited on a PET substrate that presents excellent transparency and flexibility. 
A
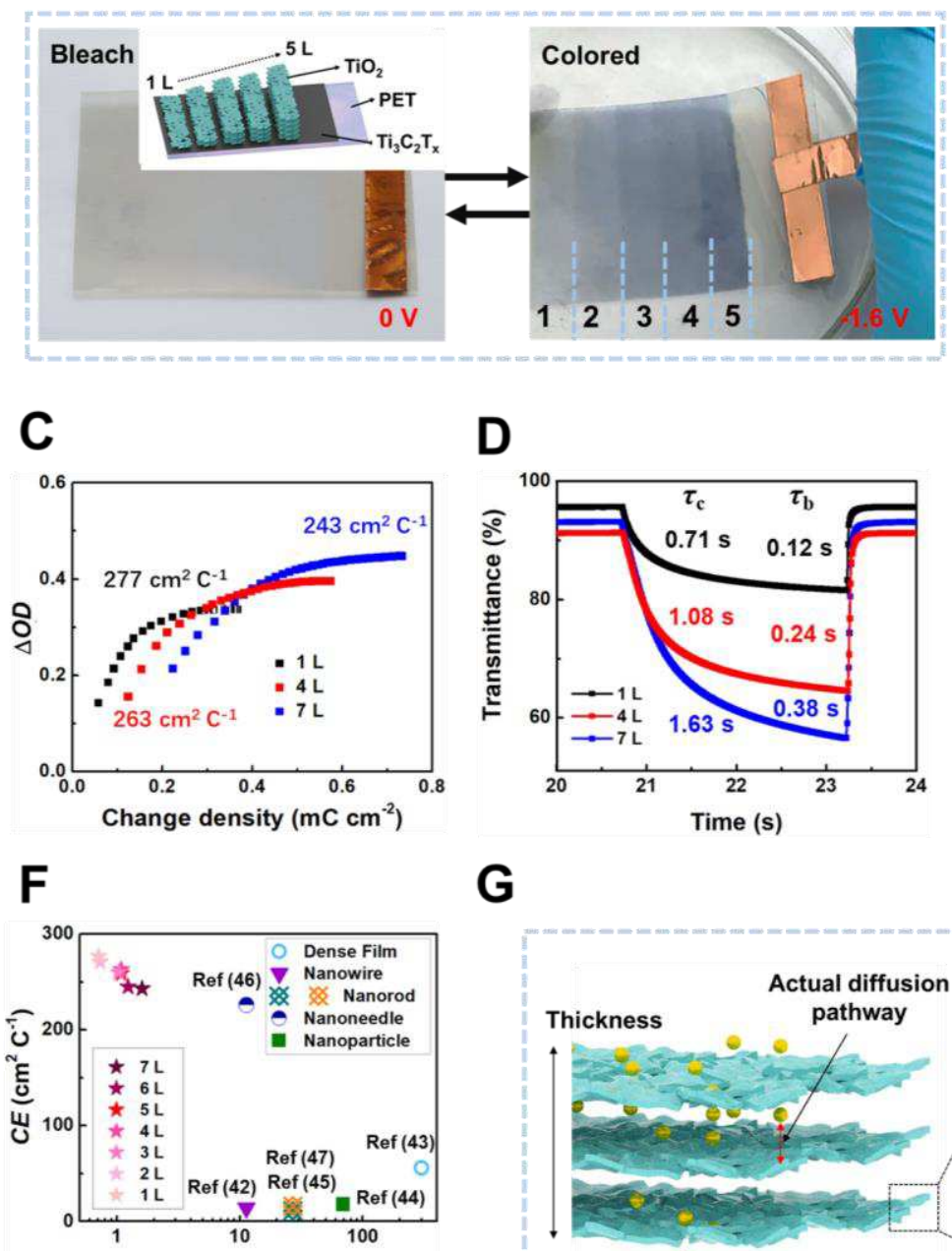

$\tau_{\mathrm{c}}(\mathbf{s})$

G

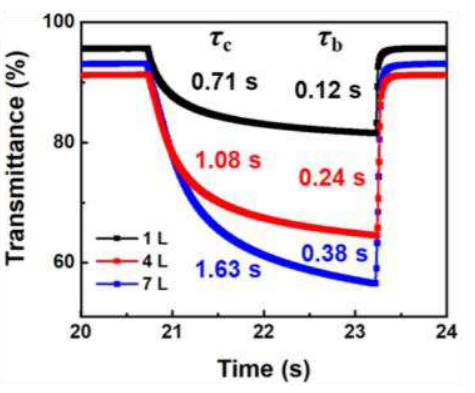

B

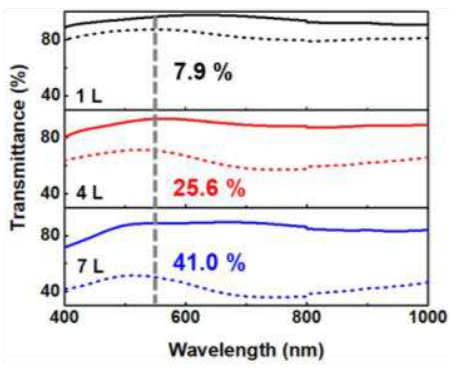

\section{E}

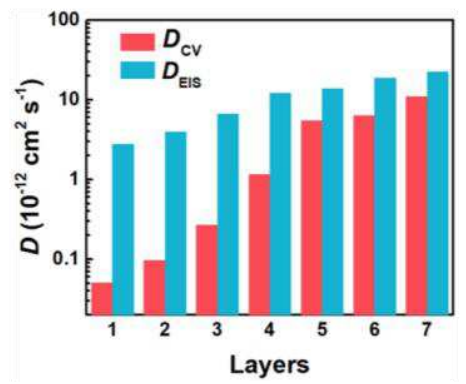

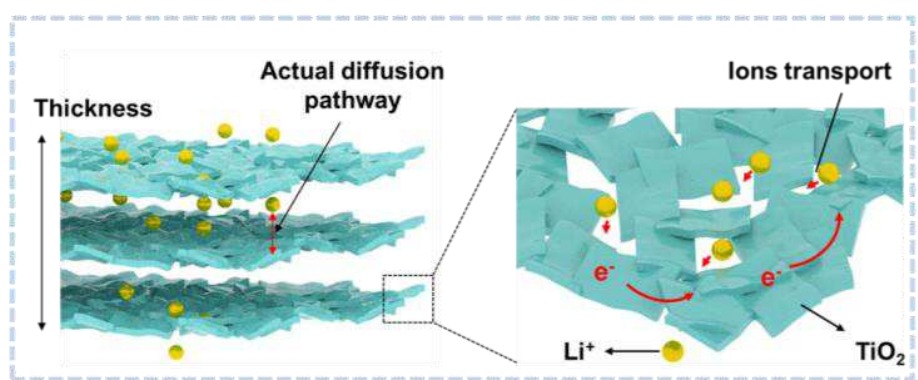

Fig. 4. Electrochromic properties of the $\mathrm{TiO}_{2} / \mathrm{Ti}_{3} \mathrm{C}_{2} \mathrm{~T}_{\mathbf{x}}$ heterostructure. (A) Photographs of the $\mathrm{TiO}_{2} / \mathrm{Ti}_{3} \mathrm{C}_{2} \mathrm{~T}_{x} / \mathrm{PET}$ film with different layers of $\mathrm{TiO}_{2}$ at the bleach state (no bias) and the colored state (biased at $-1.6 \mathrm{~V}$ ). Inset: structure of $\mathrm{TiO}_{2} / \mathrm{Ti}_{3} \mathrm{C}_{2} \mathrm{~T}_{\mathrm{x}} / \mathrm{PET}$ film with different $\mathrm{TiO}_{2}$ layers; (B) Optical transmittance spectra with 1,4 and 7 layers of $\mathrm{TiO}_{2}$ at the biases of $0 \mathrm{~V}$ (solid) and $-1.6 \mathrm{~V}$ (dotted). (C) Optical density change $(\triangle O D)$ as a function of the injected charge density for the heterostructures with 1, 4 and 7 layers of $\mathrm{TiO}_{2}$; (D) Temporal response of the transmittance at 550 $\mathrm{nm}$ of the heterostructures with 1, 4 and 7 layers of $\mathrm{TiO}_{2}$. (E) Diffusion coefficients $(D)$ of the heterostructures with 1-7 layers of $\mathrm{TiO}_{2}$ extracted from the EIS and CV measurements; (F) $C E$ as a function of coloration time $\left(\tau_{\mathrm{c}}\right)$ for the $\mathrm{TiO}_{2} / \mathrm{Ti}_{3} \mathrm{C}_{2} \mathrm{~T}_{\mathrm{x}}$ heterostructures and previously reported $\mathrm{TiO}_{2}$-based structures; (G) Schematic of the pathways of electron conduction and ion diffusion within the self-assembled $\mathrm{TiO}_{2}$ thin film. 
A

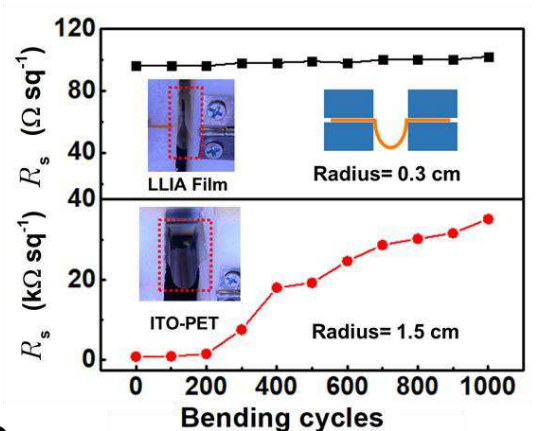

C

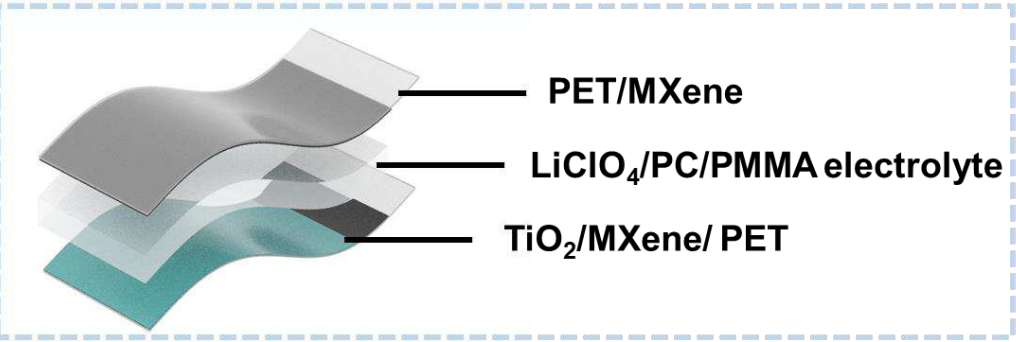

D

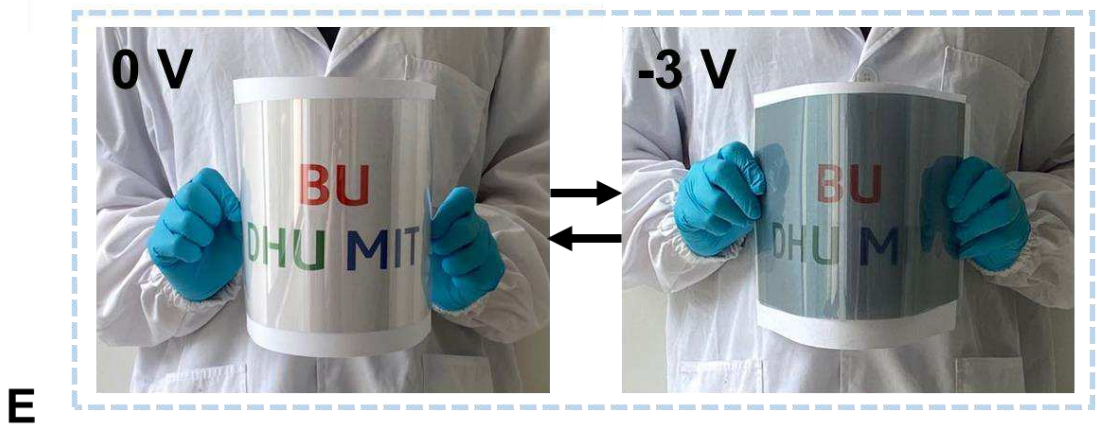

$\mathbf{E}$

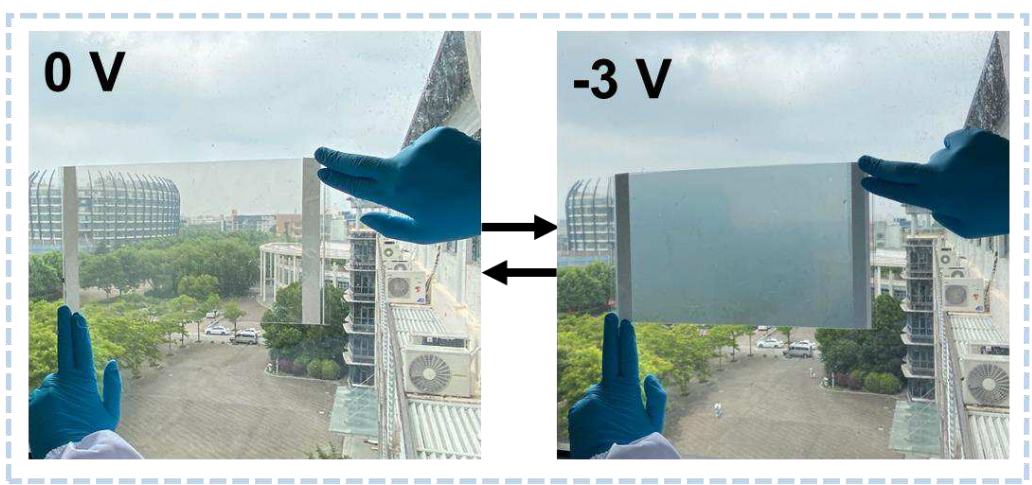

Fig. 5. Mechanical properties of the $\mathrm{TiO}_{2} / \mathrm{Ti}_{3} \mathrm{C}_{2} \mathrm{~T}_{\mathrm{x}}$ heterostructure and demonstration of a large-area flexible EC device. (A) Comparison of the sheet resistance $\left(R_{\mathrm{s}}\right)$ of the LLIA $\mathrm{Ti}_{3} \mathrm{C}_{2} \mathrm{~T}_{\mathrm{x}} / \mathrm{PET}$ and the ITO/PET films after 1000 bending cycles. (B) Comparison of the electrochromic switching behaviors of the LLIA $\mathrm{TiO}_{2} / \mathrm{Ti}_{3} \mathrm{C}_{2} \mathrm{~T}_{\mathrm{x}} / \mathrm{PET}$ and the ITO/PET films after 1000 bending cycles. (C) Schematic diagram of the flexible solid electrochromic device; (D, E) Photographs of the as-prepared solid electrochromic device with an A4 paper size (about $20 \mathrm{~cm} \times 30$ $\mathrm{cm})$. 


\section{Figures}

\section{Step 1:}

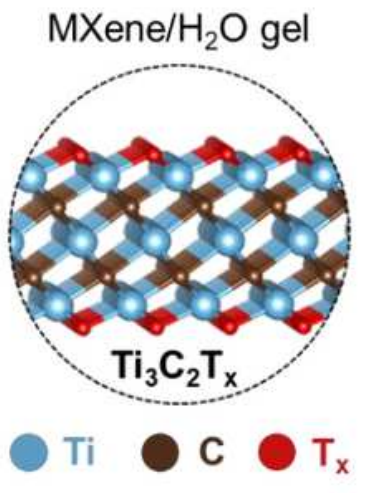

$\mathrm{T}_{\mathrm{x}}: \mathrm{O}, \mathrm{OH}, \mathrm{F}$
MXene aerogel

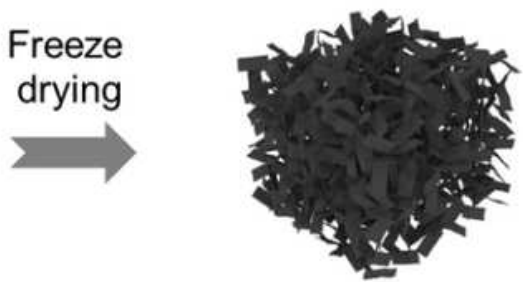

Disperse

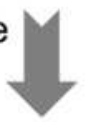

$\mathrm{TiO}_{2}$ aerogel

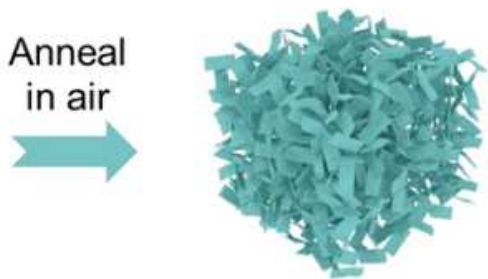

Disperse
IPA solution

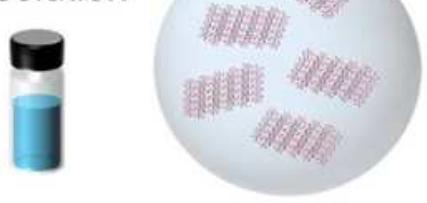

Inject

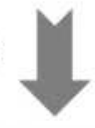

Inject

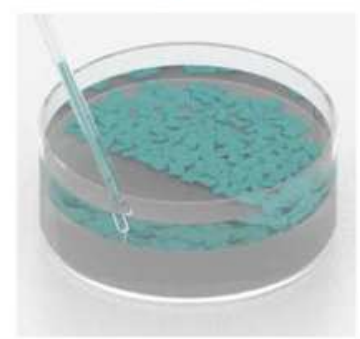

Transfer

$\mathrm{TiO}_{2} / \mathrm{M}$ Xene/PET

PET film

Transfer

MXene/PET

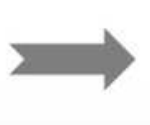

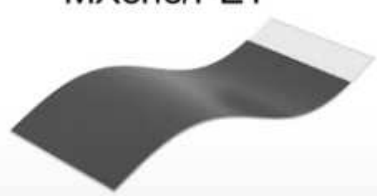

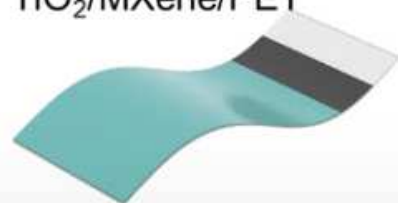

\section{Figure 1}

Fabrication process of TiO2/Ti3C2Tx heterostructure on a flexible substrate. Step 1: MXene (Ti3C2Tx) aerogel is obtained by freeze drying of the Ti3C2Tx nanosheets dispersion and the derived TiO2 aerogel is obtained by annealing the MXene aerogel in air at $400^{\circ} \mathrm{C}$. Step 2: Ti3C2Tx and TiO2 2D nanosheets are 
dispersed respectively in IPA, injected into the interface between hexene and DI water, and self-assembled into nanometer-thick $\mathrm{Ti} 3 \mathrm{C} 2 \mathrm{Tx}$ and $\mathrm{TiO} 2$ films. Step 3: the thin films are transferred onto a flexible substrate (e.g. PET) in a layer-by-layer fashion to realize the TiO2/MXene heterostructure, where the TiO2 layer serves as the electrochromic component, and the MXene layer serves as the transparent electrode.

A

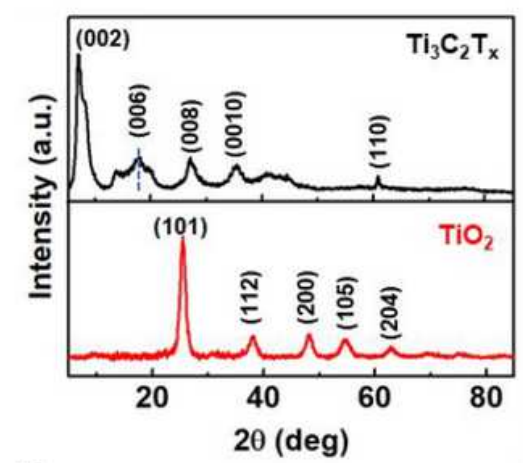

D

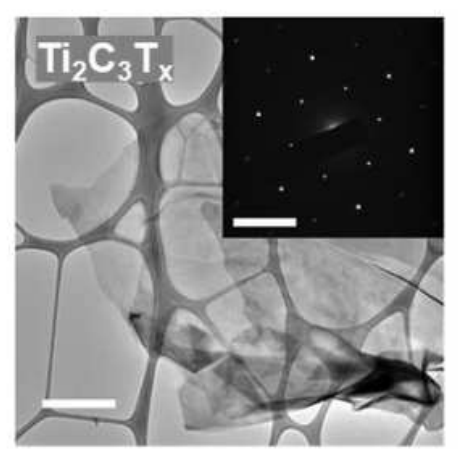

B

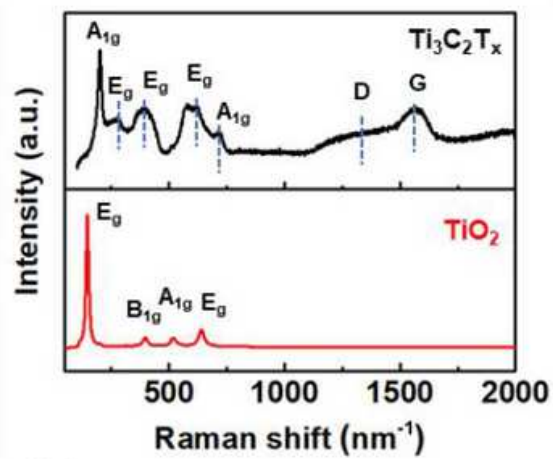

$\mathbf{E}$

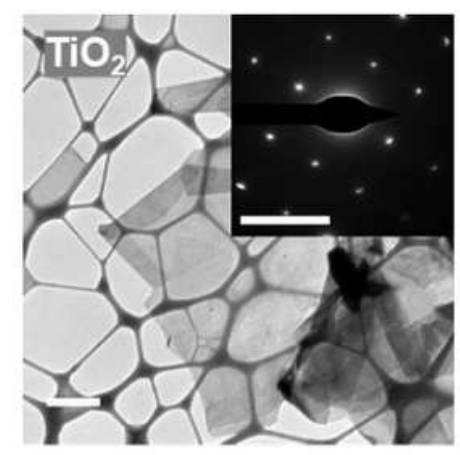

C

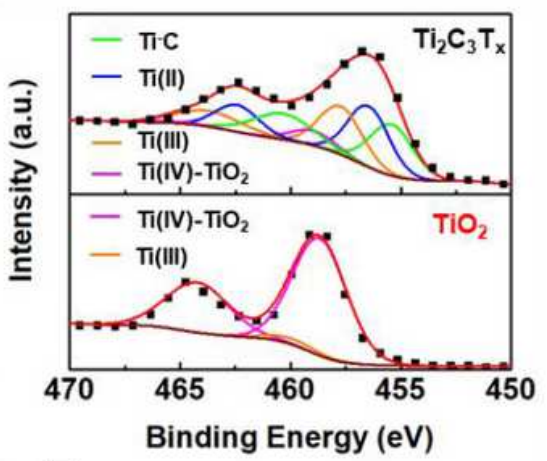

$\mathbf{F}$

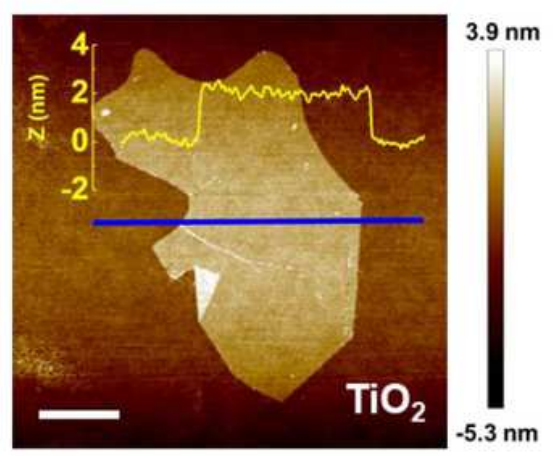

Figure 2

Conversion of Ti3C2Tx into 2D TiO2 flakes. (A) XRD patterns and (B) Raman spectra of the Ti3C2Tx before and after annealing at $400^{\circ} \mathrm{C}$ for $50 \mathrm{~h}$. (C) XPS spectra of the Ti3C2Tx and the derived TiO2. TEM images of (E) Ti3C2Tx and (F) derived TiO2 flakes on a TEM grid (scale bar: $1 \mu \mathrm{m}$ ). Insets: SEAD patterns of Ti3C2Tx and derived TiO2 flakes (scale bar: $5 \mathrm{~nm}-1$ ); (F) AFM image and height profile of a derived TiO2 flake on a SiO2/Si substrate (scale bar: $2 \mu \mathrm{m}$ ). 
A

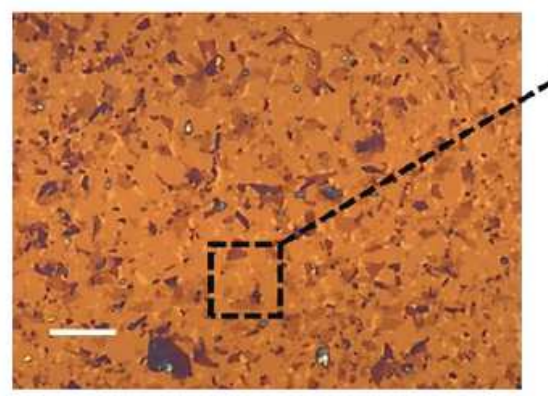

D

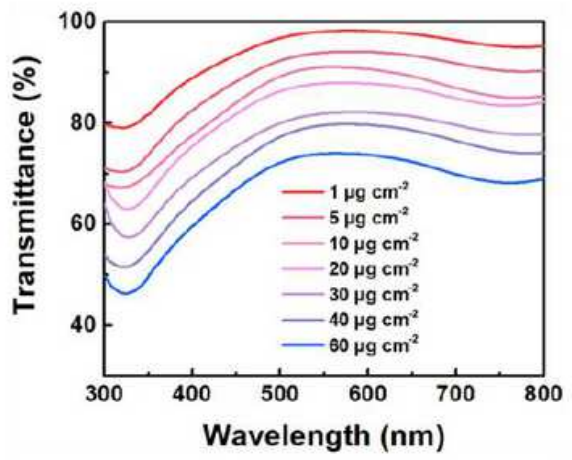

B

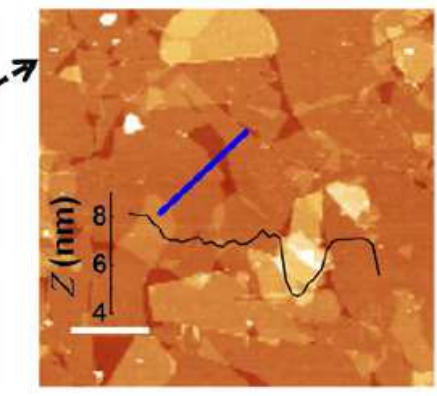

$\mathbf{E}$

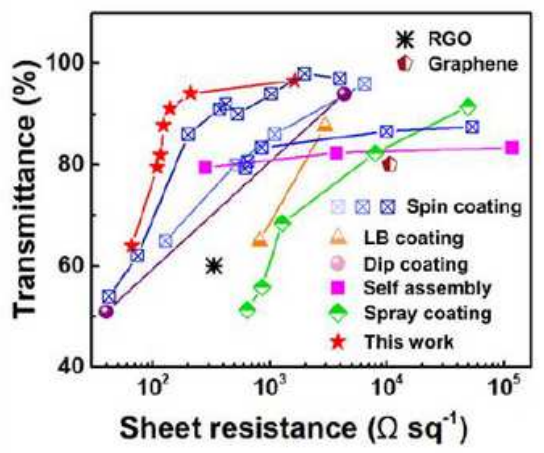

$8.6 \mathrm{~nm}$
C

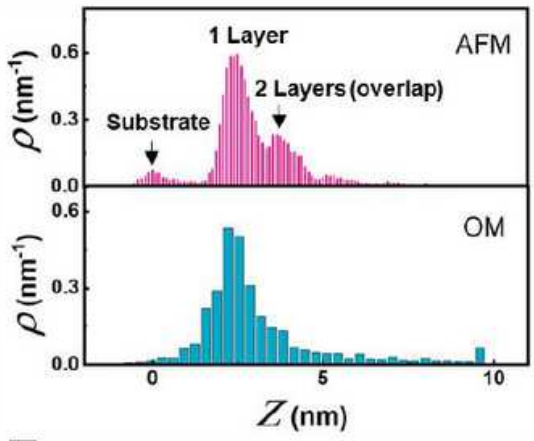

$\mathbf{F}$

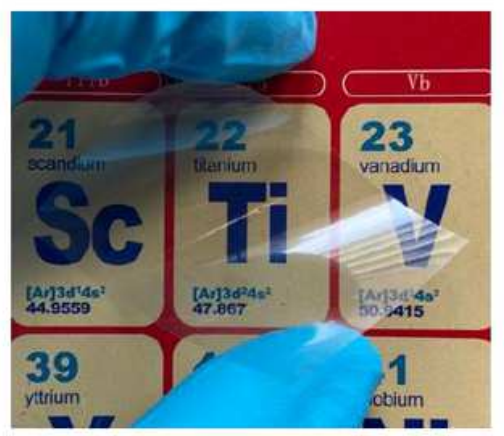

\section{Figure 3}

Characterization of the self-assembled Ti3C2Tx thin film as a transparent electrode. (A) OM image of the assembled Ti3C2Tx thin film (scale bar: $10 \mu \mathrm{m}$ ). (B) AFM image and the height profile of the assembled Ti3C2Tx thin film in corresponding area marked in (A) (scale bar: $2 \mu \mathrm{m}$ ). (C) Height distributions extracted from the AFM image (top) and the OM image (bottom); the y-axes are probability density, namely, frequency per unit height; (D) Transmittance spectra of Ti3C2Tx films with various concentrations of injected Ti3C2Tx; (E) Transmittance at $550 \mathrm{~nm}$ as a function of sheet resistance for the Ti3C2Tx films and data from previously reported transparent electrode technologies; (F) Photograph of a Ti3C2Tx film deposited on a PET substrate that presents excellent transparency and flexibility. 
A

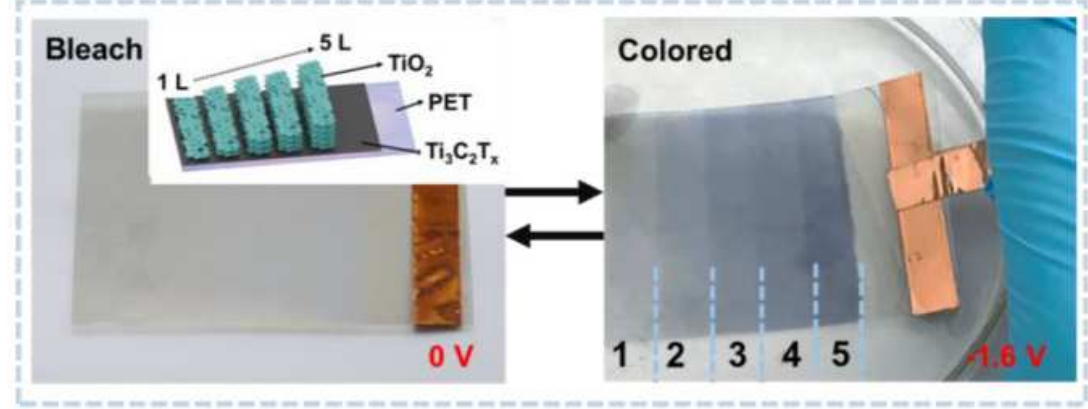

C

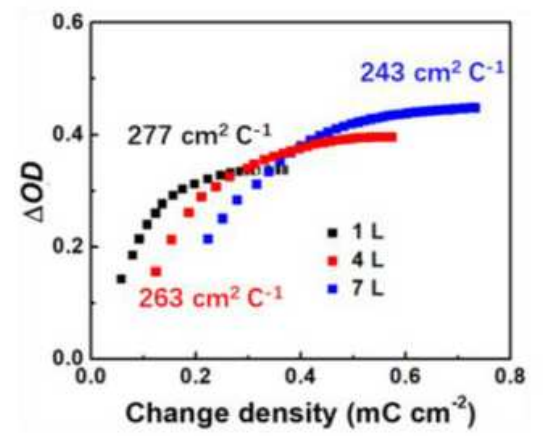

$\mathbf{F}$

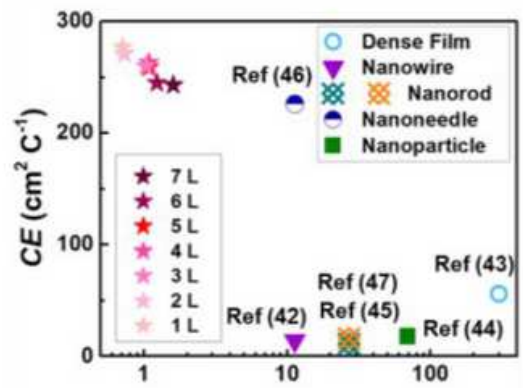

$\tau_{\mathrm{c}}(\mathrm{s})$

G

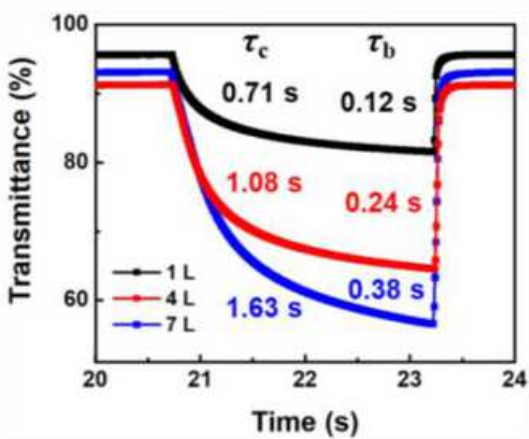

B

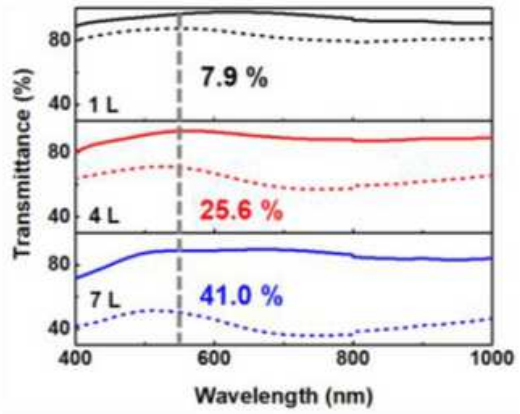

$\mathbf{E}$

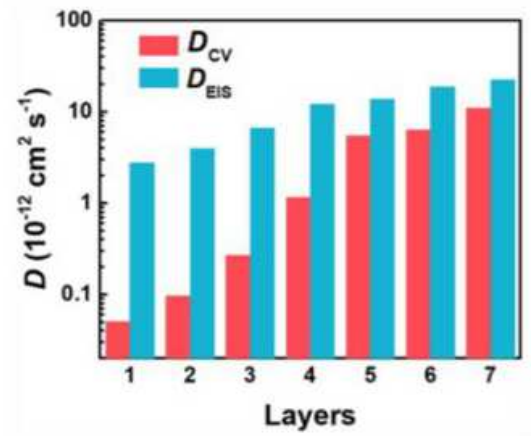

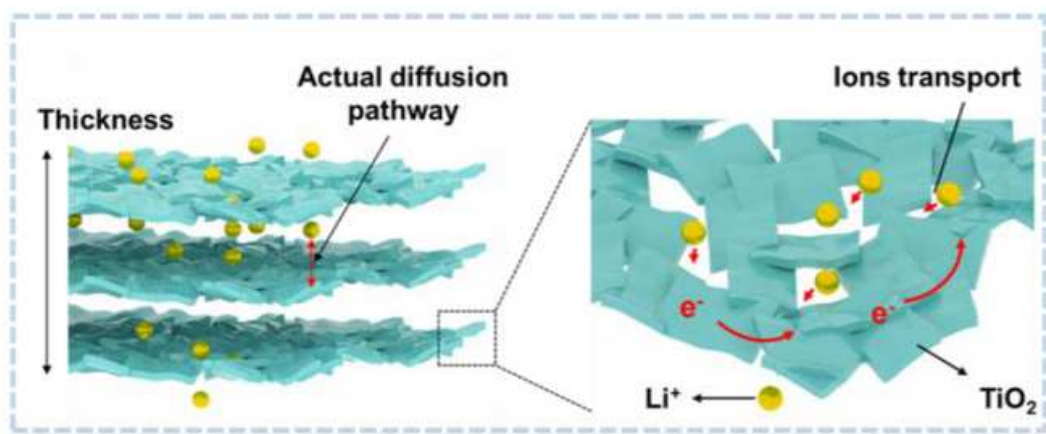

Figure 4

Electrochromic properties of the Ti02/Ti3C2Tx heterostructure. (A) Photographs of the $\mathrm{TiO} 2 / \mathrm{Ti} 3 \mathrm{C} 2 \mathrm{Tx} / \mathrm{PET}$ film with different layers of TiO2 at the bleach state (no bias) and the colored state (biased at -1.6 V). Inset: structure of Ti02/Ti3C2Tx/PET film with different TiO2 layers; (B) Optical transmittance spectra with 1, 4 and 7 layers of TiO2 at the biases of $0 \mathrm{~V}$ (solid) and $-1.6 \mathrm{~V}$ (dotted). (C) Optical density change $(\triangle O D)$ as a function of the injected charge density for the heterostructures with 1 , 4 and 7 layers of TiO2; (D) Temporal response of the transmittance at $550 \mathrm{~nm}$ of the heterostructures with 1, 4 and 7 layers of TiO2. (E) Diffusion coefficients (D) of the heterostructures with 187 layers of TiO2 extracted from the EIS and CV measurements; (F) CE as a function of coloration time (TC) for the TiO2/Ti3C2Tx heterostructures and previously reported TiO2-based structures; (G) Schematic of the pathways of electron conduction and ion diffusion within the self-assembled TiO2 thin film. 
A

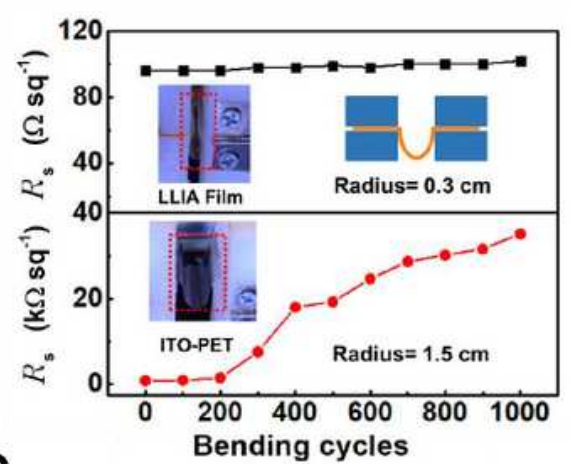

C

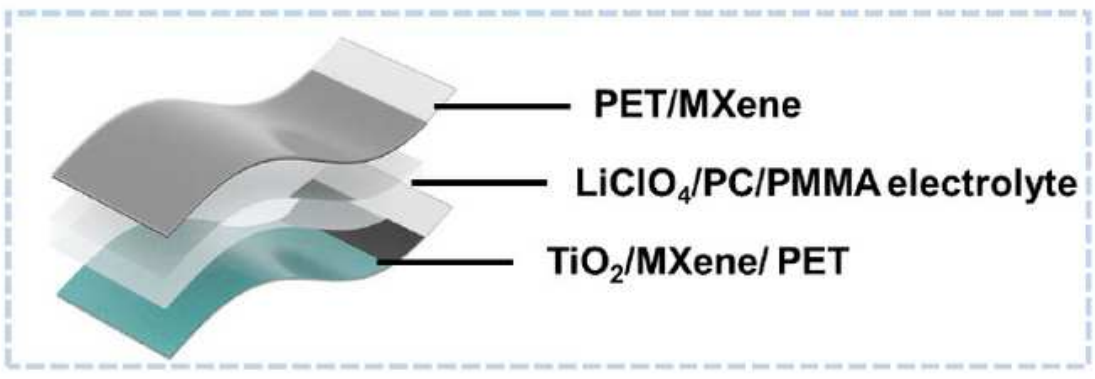

D

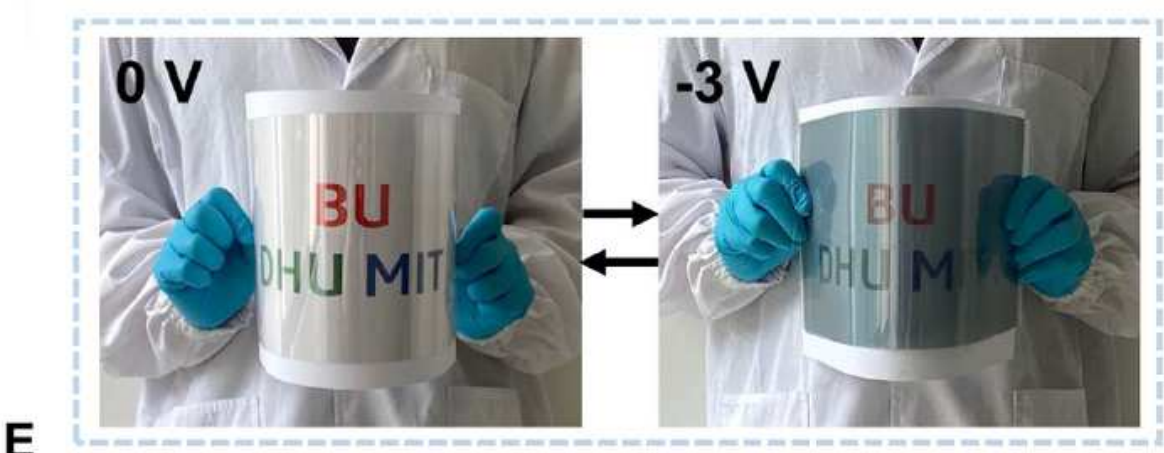

E

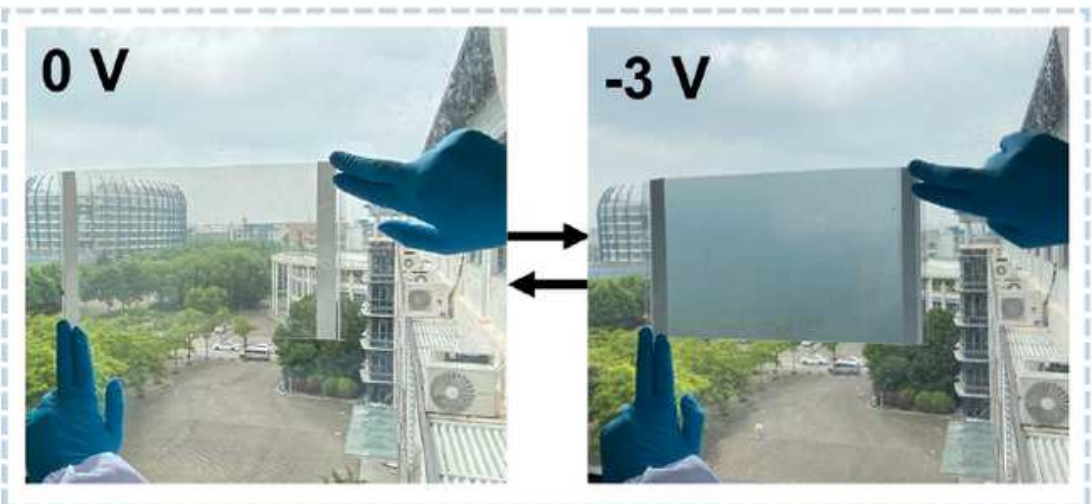

\section{Figure 5}

Mechanical properties of the $\mathrm{TiO} 2 / \mathrm{Ti} 3 \mathrm{C} 2 \mathrm{Tx}$ heterostructure and demonstration of a large-area flexible EC device. (A) Comparison of the sheet resistance (Rs) of the LLIA Ti3C2TX/PET and the ITO/PET films after 1000 bending cycles. (B) Comparison of the electrochromic switching behaviors of the LLIA TiO2/Ti3C2Tx/PET and the ITO/PET films after 1000 bending cycles. (C) Schematic diagram of the 
flexible solid electrochromic device; (D, E) Photographs of the as-prepared solid electrochromic device with an A4 paper size (about $20 \mathrm{~cm} \times 30 \mathrm{~cm}$ ).

\section{Supplementary Files}

This is a list of supplementary files associated with this preprint. Click to download.

- SI.pdf 